\title{
Net community production and gross primary production rates in the western equatorial Pacific
}

\author{
Rachel H. R. Stanley, ${ }^{1,2}$ John B. Kirkpatrick, ${ }^{3}$ Nicolas Cassar, ${ }^{1,4}$ Bruce A. Barnett, ${ }^{1}$ \\ and Michael L. Bender ${ }^{1}$ \\ Received 9 August 2009; revised 20 January 2010; accepted 11 March 2010; published 12 October 2010.
}

[1] Net community production (NCP) and gross primary production (GPP) are two key metrics for quantifying the biological carbon cycle. In this study, we present a detailed characterization of NCP and GPP in the western equatorial Pacific during August and September 2006. We use continuous measurements of dissolved gases $\left(\mathrm{O}_{2}\right.$ and $\left.\mathrm{Ar}\right)$ in the surface water in order to quantify NCP at subkilometer scale resolution. We constrain GPP in discrete samples using the triple isotopic composition of $\mathrm{O}_{2}$. We find the average NCP in the western equatorial Pacific is $5.9 \pm 0.9 \mathrm{mmol} \mathrm{O}_{2} \mathrm{~m}^{-2} \mathrm{~d}^{-1}$ (equivalent to $1.5 \pm 0.2 \mathrm{~mol} \mathrm{C} \mathrm{m}{ }^{-2} \mathrm{yr}^{-1}$ with error estimates reflecting $1 \sigma$ confidence levels) and the average GPP is $121 \pm 34 \mathrm{mmol} \mathrm{O}_{2} \mathrm{~m}^{-2} \mathrm{~d}^{-1}$ (equivalent to $32 \pm 9 \mathrm{~mol} \mathrm{C}$ $\left.\mathrm{m}^{-2} \mathrm{yr}^{-1}\right)$. The measurements reveal significant spatial variability on length scales as small as $50 \mathrm{~km}$. The NCP/GPP ratio is $5.7 \% \pm 1.8 \%$. We also present results for NCP and GPP in the coastal area off Papua New Guinea and for GPP in the central Pacific along the equator.

Citation: Stanley, R. H. R., J. B. Kirkpatrick, N. Cassar, B. A. Barnett, and M. L. Bender (2010), Net community production and gross primary production rates in the western equatorial Pacific, Global Biogeochem. Cycles, 24, GB4001, doi:10.1029/2009GB003651.

\section{Introduction}

[2] The ocean plays a fundamental role in the natural cycle of $\mathrm{CO}_{2}$. Biological productivity draws down carbon in the upper ocean. Some fraction of the carbon is exported, separating it from the surface for periods ranging from a few years to up to a thousand years. Net community production (NCP) is a measure of the net amount of carbon removed from the atmosphere via this biological pump. Gross primary production (GPP) reflects the total amount of photosynthesis. Together, these two variables offer important insights into the carbon cycle.

[3] The equatorial Pacific is an important region in which to study NCP and GPP because the region is the largest oceanic source of $\mathrm{CO}_{2}$ to the atmosphere [Takahashi et al., 1997; 2002]. In addition, the region is very productive, accounting for approximately $20 \%$ of global productivity [Chavez and Barber, 1987; Behrenfeld et al., 2006]. Thus,

\footnotetext{
${ }^{1}$ Department of Geosciences, Princeton University, Princeton, New Jersey, USA.

${ }^{2}$ Now at Department of Marine Chemistry and Geochemistry, Woods Hole Oceanographic Institution, Woods Hole, Massachusetts, USA.

${ }^{3}$ School of Oceanography, University of Washington, Seattle, Washington, USA.

${ }^{4}$ Now at Division of Earth and Ocean Sciences, Duke University, Durham, North Carolina, USA.

Copyright 2010 by the American Geophysical Union. 0886-6236/10/2009GB003651
}

the equatorial Pacific has both large $\mathrm{CO}_{2}$ sources and sinks. These large fluxes are concentrated in the eastern and central equatorial Pacific, an upwelling region which has been well studied by individual investigators as well as by the JGOFS program [Murray et al., 1995]. The eastern and central equatorial Pacific is a high-nitrate low-chlorophyll (HNLC) region where production is believed to be limited by iron [Coale et al., 1996] and perhaps by silicate as well [Dugdale and Wilkerson, 1998; Chai et al., 2002; 2007; Dugdale et al., 2007]. Short-term variability of production in this eastern region has been associated with physical instabilities in the form of tropical instability waves [Murray et al., 1994]. Longer-term variability includes a reduction in biological production associated with El Niño events but not any corresponding increase during La Niña events [Strutton et al., 2008], as well as variability associated with the Pacific Decadal Oscillation [Takahashi et al., 2003; Feely et al., 2006].

[4] Relatively few measurements of biological productivity have been made in the western equatorial Pacific (WEP), here defined as the region west of the date line and east of Papua New Guinea. This study aims to help fill this gap by providing a detailed characterization of biological productivity in this region during the months of August and September in a weak El Niño year. Because the seasonality in the WEP is weak, this time period is representative of most of the year, except for the early spring where there is a peak in chlorophyll and thus probably in productivity as well [Strutton et al., 2008]. Upwelling does not extend this 
far west, and thus, the WEP is noted for warmer temperatures and lower nutrient concentrations than the east. Additionally, the phytoplankton community differs, with the WEP being dominated by Prochlorococcus versus Synechcococcus and picoeukaryotes in the east [Blanchot et al., 2001; Matsumoto et al., 2004]. Estimates of the biological production in the western equatorial Pacific region vary from negligible values to $36 \%$ of production in the eastern equatorial Pacific [Le Borgne et al., 2002]. It has been hypothesized that production in this low-nutrient region would depend on nitracline depth [Turk et al., 2001; Le Borgne et al., 2002].

[5] Dissolved gases are valuable tracers for assessing biological productivity. Gases integrate over the time scale of air-sea gas exchange, approximately 1-2 weeks, and thus give an overview of recent production that can provide a different perspective than the snapshots given by bottle incubations. Oxygen and its abiotic analog, argon, have been used in tandem to quantify NCP in the upper ocean [Craig and Hayward, 1987; Emerson, 1987; Spitzer and Jenkins, 1989]. Recent advances in underway membrane inlet mass spectrometry now allow $\mathrm{O}_{2}$ and Ar concentrations to be determined continuously in surface water [Kaiser et al., 2005; Cassar et al., 2009]. The continuous dissolved gas measurements, when combined with estimates of gas exchange, yield detailed records of NCP variations along a cruise track. This method for assessing NCP cannot currently be applied in the central equatorial Pacific because of poor constraints on the upward flux of $\mathrm{O}_{2}$-undersaturated waters in this region [Hendricks et al., 2005].

[6] Mass independent reactions in the stratosphere [Thiemens et al., 1995; Lammerzahl et al., 2002] cause $\mathrm{O}_{2}$ of atmospheric origin to have a different triple isotopic signature (ratio of ${ }^{16} \mathrm{O},{ }^{17} \mathrm{O}$, and ${ }^{18} \mathrm{O}$ ) from that of photosynthetic $\mathrm{O}_{2}$. Hence, measurements of the triple isotopic composition of $\mathrm{O}_{2}$ dissolved in surface seawater, when combined with estimates of gas exchange, serve to quantify GPP [Luz et al., 1999; Luz and Barkan, 2000; Hendricks et al., 2004; 2005; Juranek and Quay, 2005; Reuer et al., 2007]. We provide estimates for GPP even in the upwelling region since the thermocline water has a similar triple isotopic signature and thus upwelling does not appreciably bias the GPP results.

[7] In this study, we use continuous measurements of dissolved $\mathrm{O}_{2}$ and $\mathrm{Ar}$ and discrete measurements of the triple isotopic composition of $\mathrm{O}_{2}$ to determine mixed layer NCP and GPP rates throughout a large swath of the equatorial Pacific Ocean, concentrating on the western equatorial Pacific. We then examine the relationship between the NCP and GPP rates and physical and biogeochemical parameters, which were measured concurrently, such as sea surface temperature, salinity, density, iron, nutrient, and chlorophyll concentrations, and photosynthetic efficiency.

\section{Methods}

[8] Samples were collected from the underway water system onboard the $R / V$ Kilo Moana during August and September 2006, as part of the Equatorial Undercurrent Iron cruise (EUC-Fe; KM0625) from Hawaii to Papua New Guinea. The cruise track zigzagged between $140^{\circ} \mathrm{W}$ and $140^{\circ} \mathrm{E}$, staying primarily within $\pm 2^{\circ}$ of the equator. Measurements of the $\mathrm{O}_{2} / \mathrm{Ar}$ ratio were made continuously along the cruise track, and measurements of oxygen isotopes were made approximately every $12 \mathrm{~h}$ or every $2^{\circ}$. Additionally, at 30 stations, bottle samples were collected for nutrients $\left(\mathrm{NO}_{3}, \mathrm{NO}_{2}, \mathrm{NH}_{4}, \mathrm{PO}_{4}, \mathrm{Si}\right)$, chlorophyll, and photosynthetic efficiency $\left(F_{\mathrm{v}} / F_{\mathrm{m}}\right)$.

[9] In section 2.1, we describe the methods for measuring the dissolved gases in the surface water. In section 2.2, we briefly discuss the equations used to calculate NCP and GPP from the gas tracers. In section 2.3, we describe the ancillary data sets to which we compare our NCP rates.

\subsection{Dissolved Gas Measurements}

[10] Surface water concentrations of $\mathrm{O}_{2}$ and $\mathrm{Ar}$ were measured continuously from the underway water system by an Equilibrator Inlet Mass Spectrometer (EIMS) [Kaiser et al., 2005; Cassar et al., 2009]. Water from the underway system (intake on bow of ship at $8 \mathrm{~m}$ depth) was pumped into the laboratory. The water was then pumped through tygon tubing into an equilibrator cartridge (MicroModule ${ }^{\circledR}$ $0.75 \times 1$ ) at a speed of $100 \mathrm{~cm}^{3} \mathrm{~min}^{-1}$ using a gear pump, where dissolved gas equilibrated with the cartridge headspace. The headspace gas was pumped through a fused silica capillary (0.05 $\mathrm{mm}$ diameter, $2 \mathrm{~m}$ length) into a quadrupole mass spectrometer (Pfeiffer Prisma model QMS 200 M1) where $\mathrm{O}_{2}, \mathrm{Ar}$, and $\mathrm{N}_{2}$ ion currents were measured. Measurements were made every $8 \mathrm{~s}$ and averaged into $2 \mathrm{~min}$ intervals. The $e$-folding response time of the EIMS system is approximately $7 \mathrm{~min}$ due to the time it takes for gases to equilibrate across the membrane [Cassar et al., 2009], and thus, though we have data at $2 \mathrm{~min}$ intervals, the $2 \mathrm{~min}$ data may reflect some averaging of the real signals. For example, fronts or transitions that occurred at less than $2 \mathrm{~km}$ spatial scale (where $2 \mathrm{~km}$ corresponds to $7 \mathrm{~min}$ of a ship travelling at 10 knots) may be blurred.

[11] The EIMS was calibrated with samples collected from the underway system approximately every $6 \mathrm{~h}$. Samples were collected in preevacuated glass bottles [Emerson et al., 1995], which had been poisoned with $\mathrm{HgCl}_{2}$. Approximately half of the bottles samples were analyzed for $\mathrm{O}_{2} / \mathrm{Ar}$ and the triple isotopic composition of oxygen and the other half were analyzed for $\mathrm{O}_{2} / \mathrm{Ar}$ and $\mathrm{O}_{2} / \mathrm{N}_{2}$ using isotope ratio mass spectrometers at Princeton University (Finnigan MAT 252 and Finnigan Delta-X Plus, respectively). The samples were analyzed using the methods described by Hendricks et al. [2005] and Reuer et al. [2007]. Samples were measured within three months of collection to minimize problems related to gases diffusing through the valves of the sample storage flasks [Hendricks et al., 2005; Reuer et al., 2007]. Reproducibility for the bottle samples as determined from the standard deviation of multiple equilibrated laboratory water samples analyzed at the same time as the samples was $0.3 \%$ for $\mathrm{O}_{2} / \mathrm{Ar}$ measurements and 7 per meg for oxygen triple isotope measurements. Measurements of a suite of samples taken concurrently from the CTD rosette and from the underway system were statistically similar, signifying that there were no biases in the underway water. 


\subsection{Calculating Production Rates From Dissolved Gases}

[12] Outside of upwelling zones, $\mathrm{O}_{2} / \mathrm{Ar}$ ratios in the mixed layer primarily reflect the balance between NCP and gas exchange, whereas triple isotope measurements reflect the balance between GPP and gas exchange. A detailed explanation of how these tracers are used to calculate NCP and GPP has been published elsewhere [Hendricks et al., 2004; 2005; Juranek and Quay, 2005; Reuer et al., 2007], so here we limit ourselves to a brief explanation.

[13] The biological oxygen saturation $\Delta\left(\mathrm{O}_{2} / \mathrm{Ar}\right)$ is calculated according to

$$
\Delta\left(\mathrm{O}_{2} / \mathrm{Ar}\right)=\left[\left(\mathrm{O}_{2} / \mathrm{Ar}\right)_{\mathrm{smpl}} /\left(\mathrm{O}_{2} / \mathrm{Ar}\right)_{\mathrm{eq}}-1\right],
$$

where $\left(\mathrm{O}_{2} / \mathrm{Ar}\right)_{\text {smpl }}$ is the ratio of $\mathrm{O}_{2}$ and $\mathrm{Ar}$ ion currents as determined from the EIMS, calibrated according to the bottle samples, and $\left(\mathrm{O}_{2} / \mathrm{Ar}\right)_{\mathrm{eq}}$ is the ratio of equilibrium concentrations of the gases determined from the solubility of the gases [Garcia and Gordon, 1992; Hamme and Emerson, 2004].

[14] Net community production (NCP), in units of mmol $\mathrm{O}_{2} \mathrm{~m}^{-2} \mathrm{~d}^{-1}$, is then calculated according to

$$
\mathrm{NCP}=\Delta\left(\mathrm{O}_{2} / \mathrm{Ar}\right)\left[\mathrm{O}_{2}\right]_{\mathrm{eq}} \mathrm{k} \rho,
$$

where $\left[\mathrm{O}_{2}\right]_{\text {eq }}$ is the equilibrium concentration of $\mathrm{O}_{2}$ at the relevant temperature and salinity $\left(\mathrm{mmol} \mathrm{kg}^{-1}\right), k$ is the gas transfer velocity $\left(\mathrm{m} \mathrm{d}^{-1}\right)$, and $\rho$ is the density of seawater $\left(\mathrm{kg} \mathrm{m}^{-3}\right)$ [Millero and Poisson, 1981]. The gas transfer velocity is a weighted average of the gas transfer velocities calculated from the past 60 days, as described by Reuer et al. [2007]. Each gas transfer velocity was calculated from QuikSCAT satellite winds and a quadratic gas exchange relationship, which has a diffusive gas exchange component that is similar to the parameterization of Wanninkhof [1992] but scaled by a factor of 0.97 [Stanley et al., 2006; Stanley, 2007; Stanley et al., 2009]. We omit any explicit consideration of air injection because $\mathrm{O}_{2}$ and Ar have similar solubilities and diffusivities. Thus, we do not need to discriminate between warming and air injection as the cause of physical supersaturation of $\mathrm{O}_{2}$ and $\mathrm{Ar}$.

[15] The triple isotopic composition of oxygen ${ }^{17} \Delta$ is given by

$$
{ }^{17} \Delta=\left[\ln \left(\delta^{17} \mathrm{O} / 1000+1\right)-\lambda \ln \left(\delta^{18} \mathrm{O} / 1000+1\right)\right] \times 10^{6},
$$

where $\delta^{17} \mathrm{O}$ and $\delta^{18} \mathrm{O}$ reflect standard isotopic notation $\left(\delta^{x} \mathrm{O}=\left(\left({ }^{x} \mathrm{O} /{ }^{16} \mathrm{O}\right)_{\mathrm{smpl}} /\left({ }^{x} \mathrm{O} /{ }^{16} \mathrm{O}\right)_{\mathrm{std}}-1\right) \times 1000\right)$ and $\lambda$, which equals 0.518 [Luz and Barkan, 2005], is the value characterizing the isotopic fractionation associated with dark respiration in a steady state system.

[16] The rate of GPP, in units of mmol $\mathrm{O}_{2} \mathrm{~m}^{-2} \mathrm{~d}^{-1}$, is equal to

$$
\mathrm{GPP}=\left[\mathrm{O}_{2}\right]_{\mathrm{eq}} k\left({ }^{17} \Delta_{\mathrm{eq}}-{ }^{17} \Delta_{\text {smpl }}\right) /\left({ }^{17} \Delta_{\text {smpl }}-{ }^{17} \Delta_{\text {photo }}\right),
$$

where ${ }^{17} \Delta_{\text {eq }}$ is the isotopic ratio of dissolved $\mathrm{O}_{2}$ in equilibrium with air $=8$ per meg (see Appendix A), ${ }^{17} \Delta_{\text {smpl }}$ is the isotopic ratio measured in the samples, and ${ }^{17} \Delta_{\text {photo }}$ is the isotopic ratio of oxygen produced from photosynthesis (249 per meg), which is equal to the maximum possible value of ${ }^{17} \Delta$ in seawater.

[17] The ratio of NCP/GPP can be directly calculated from the dissolved gas measurements, obviating the need to estimate gas exchange:

$\mathrm{NCP} / \mathrm{GPP}=\rho \Delta\left(\mathrm{O}_{2} / \mathrm{Ar}\right)\left({ }^{17} \Delta_{\text {smpl }}-{ }^{17} \Delta_{\text {photo }}\right) /\left({ }^{17} \Delta_{\text {eq }}-{ }^{17} \Delta_{\text {smpl }}\right)$.

Because there is an uncertainty of $\pm 15 \%$ in the gas transfer velocity, the NCP/GPP ratios reported here have less uncertainty than the individual estimates of NCP or GPP.

\subsection{Ancillary Measurements}

[18] We compare our NCP and GPP data to other measurements made on the same cruise. Continuous records of sea surface temperature and salinity were measured by the $R / V$ Kilo Moana's underway system (8 $\mathrm{m}$ depth). We calculate sea surface density according to the equation by Millero and Poisson [1981].

[19] Mixed layer depths were calculated at the stations from CTD density profiles, with the criterion of a density difference between surface and the bottom of the mixed layer of $0.125 \mathrm{~kg} \mathrm{~m}^{-3}$. At locations between stations, mixed layer depths were calculated by interpolating mixed layer depths determined from ARGOs floats (Gustavo Goni, personal communication) which were within $\pm 100 \mathrm{~km}$ and \pm 6 days of the cruise track (number of floats in that window $=16 \pm 7$ ).

[20] Satellite primary production data were determined from the VGPM algorithm of Behrenfeld and Falkowski [1997] and were downloaded from http://www.science.oregonstate.edu/ocean.productivity/index.php. The VGPM results are reported in 8 day increments. We took VGPM data for the 8 days that contained a given section of cruise track and performed a two-dimensional interpolation from the VGPM grid size $\left(0.0833^{\circ}\right)$ to the ship position. Satellite chlorophyll a was interpolated in a similar manner from Level 3 Binned 8 day SeaWiFS data, obtained from http:// oceancolor.gsfc.nasa.gov/ftp.html.

[21] At 30 stations, measurements were made by other researchers for dissolved Fe [Slemons et al., 2010], $F_{\mathrm{v}} / F_{\mathrm{m}}$ (Zackary Johnson, personal communication), primary production from ${ }^{14} \mathrm{C}$ incubations (Veronica Lance, personal communication), $\mathrm{O}_{2}, \mathrm{PO}_{4}$ and $\mathrm{Si}$ (by method of Strickland and Parsons [1972]), $\mathrm{NO}_{3}$ (by method of Armstrong et al. [1967]), and $\mathrm{NH}_{4}$ (by method of Slawyk and Macisaac [1972]).We investigate possible correlations between these measurements and the NCP and GPP rates reported here.

\section{Results}

[22] For the purposes of this paper, we will present and discuss the results for three regions within the equatorial Pacific: (1) the central equatorial Pacific (CEP), defined here as the region between $140^{\circ} \mathrm{W}$ and $180^{\circ}$, (2) the western equatorial Pacific (WEP), defined here as the region between $180^{\circ}$ and $153^{\circ} \mathrm{E}$, and (3) the area near Papua New Guinea (PNG), defined here as the region west of $153^{\circ} \mathrm{E}$. 


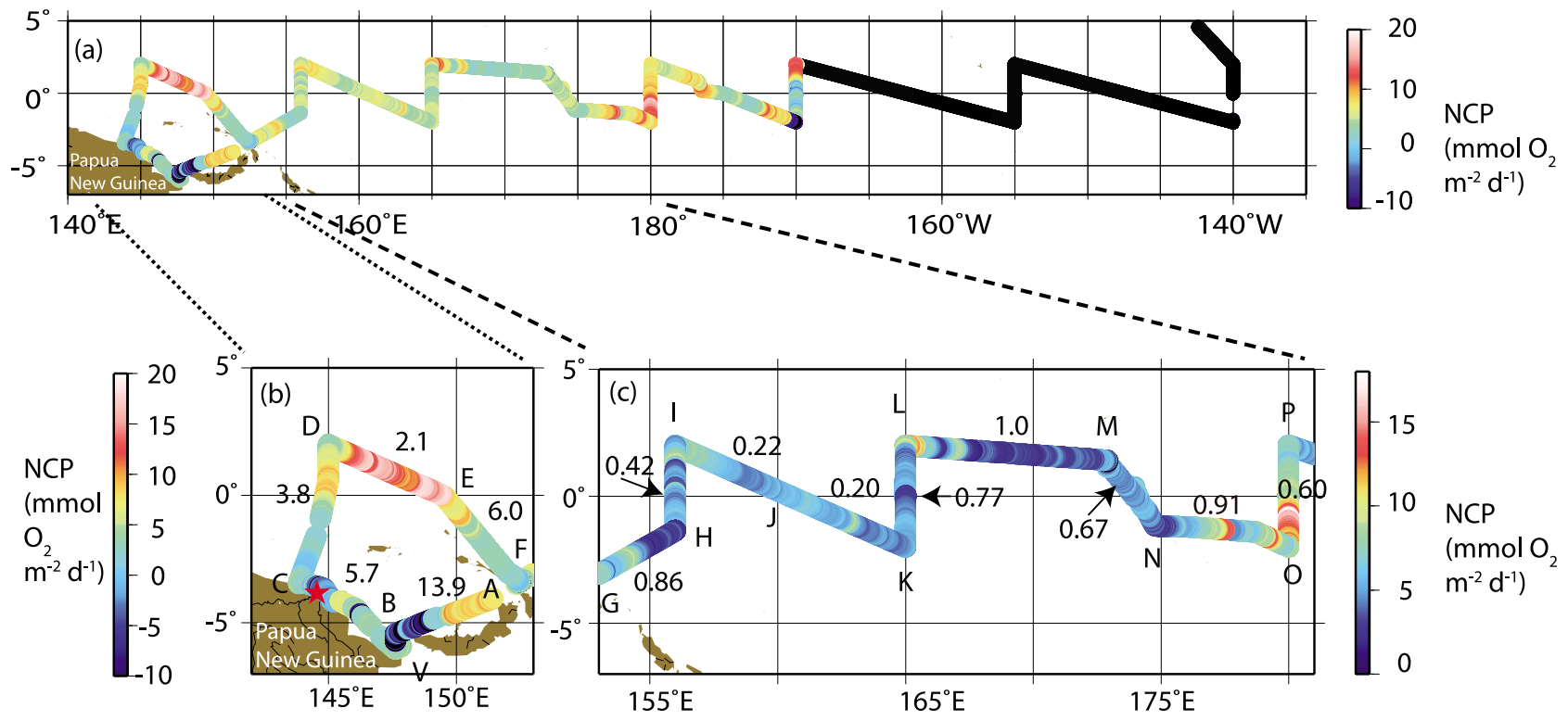

Figure 1. (a) Net Community Production (NCP) rates throughout the equatorial Pacific, with negative and "blacked-out" values in the central equatorial Pacific reflecting upwelling rather than net heterotrophy. The same data are plotted (b) in larger format for the region near Papua New Guinea region and (c) in larger format and with a different color scale for the western equatorial Pacific. The numbers reflect the variance-to-mean ratio of NCP along sections of the cruise track. In Figure 1b, the red star denotes the location of the Sepik river and the black star denotes the Vitiaz Strait. The letters correspond to the positions of the data in Figures 4 and 5.

[23] The CEP is an upwelling zone, where the introduction of $\mathrm{O}_{2}$-undersaturated waters makes the simple NCP method employed here inappropriate, but where the GPP method is still valid. Because there is a much smaller vertical gradient in triple oxygen isotopes than in $\mathrm{O}_{2} / \mathrm{Ar}$ ratios [Hendricks et al., 2005], a simple calculation using a vertical upwelling velocity of $2 \times 10^{-5} \mathrm{~m} \mathrm{~s}^{-1}$ [Johnson et al., 2001] and previously published triple oxygen isotope profiles from $140^{\circ} \mathrm{W}$ [Hendricks et al., 2005] shows that the effect of upwelling on triple oxygen isotopes is negligible. If the upwelling fluxes were known well enough, then the data collected here could be used to quantify NCP even in the $\mathrm{CEP}$, but it is questionable whether the upwelling fluxes can currently be estimated to the necessary precision.

[24] The WEP should not feel significant upwelling effects. However, small amounts of vertical mixing could exist in these waters, making our NCP estimates a lower bound. $P N G$ is a coastal region that has different water masses and is subject to the effect of the rivers and other terrigenous inputs.

[25] In Figure 1a, we present an overview of NCP rates throughout all three of these regions. We have "blacked out" the rates to the east of $170^{\circ} \mathrm{W}$ in the central equatorial Pacific because of the upwelling of $\mathrm{O}_{2}$ debt. We chose $170^{\circ} \mathrm{W}$ as the "cutoff" point because Meinen et al. [2001] showed the vertical upwelling decreases as one goes west, falling to below $0.5 \times 10^{-5} \mathrm{~m} \mathrm{~s}^{-1}$ west of $170^{\circ} \mathrm{W}$. To be conservative, however, we do not quantitatively interpret any NCP data east of 180 .
[26] Detailed views of NCP in the PNG (Figure 1b) and in the WEP (Figure 1c) show significant heterogeneity in NCP, with rates at times differing by a factor of 2 over a distance of less than $50 \mathrm{~km}$. The variance-to-mean ratio along sections of the cruise track (Figures $1 \mathrm{~b}$ and $1 \mathrm{c}$ ) is another indicator of this heterogeneity of $\mathrm{NCP}$, as this ratio often approaches 1 in the WEP and at times exceeds 10 for PNG. [27] The average NCP in the WEP is $5.9 \pm 0.9 \mathrm{mmol} \mathrm{O}_{2}$ $\mathrm{m}^{-2} \mathrm{~d}^{-1}$ (equivalent to $1.5 \pm 0.2 \mathrm{~mol} \mathrm{C} \mathrm{m}^{-2} \mathrm{yr}^{-1}$ when converted using a photosynthetic quotient of 1.4 [ $\mathrm{Laws}$, 1991] and assuming constant NCP throughout the year, where this $1 \sigma$ uncertainty is the combination of the uncertainty due to gas exchange parameterization $(15 \%), \mathrm{O}_{2} / \mathrm{Ar}$ measurement precision $(0.3 \%)$, root mean square error of correction factor $(0.3 \%)$, and the standard error of the multiple measurements taken $(0.006 \%)$. The standard deviation of NCP in the WEP is $2.6 \mathrm{mmol} \mathrm{O}_{2} \mathrm{~m}^{-2} \mathrm{~d}^{-1}$, which is much higher than the uncertainty in the average and reflects the variability in NCP in this region. The average NCP for PNG is $4.8 \pm 0.6 \mathrm{mmol} \mathrm{O}_{2} \mathrm{~m}^{-2} \mathrm{~d}^{-1}$ (equivalent to $1.2 \pm 0.2 \mathrm{~mol} \mathrm{C}$ $\left.\mathrm{m}^{-2} \mathrm{yr}^{-1}\right)$. The average is somewhat deceptive, however, as this region contains some of the highest NCP values in the north and some of the lowest NCP values near the coastline. The standard deviation of NCP in the PNG is $6.0 \mathrm{mmol} \mathrm{O}_{2}$ $\mathrm{m}^{-2} \mathrm{~d}^{-1}$.

[28] Rates of GPP range from 10 to $365 \mathrm{mmol} \mathrm{O}_{2} \mathrm{~m}^{-2} \mathrm{~d}^{-1}$, with the largest rates in the CEP and the smallest rates in the WEP (Figure 2). Although the data are sparse, it appears that the largest GPP rates occur just to the west of the upwelling 


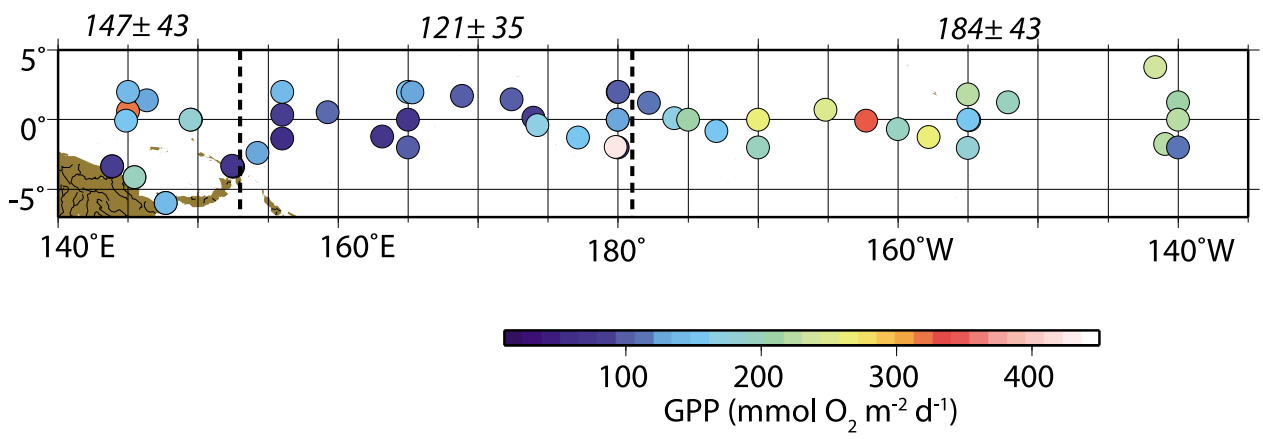

Figure 2. Gross primary production (GPP) rates throughout the equatorial Pacific, as calculated from the triple isotopic composition of $\mathrm{O}_{2}$. Italic numbers note the average GPP in each of the three regions demarcated by the dashed lines. The listed $1 \sigma$ uncertainty estimates reflect the combination of spatial variability in the GPP rates as well as method uncertainty.

zone. One explanation could be that there are sufficient major nutrients for production but also more $\mathrm{Fe}$ than in the heart of the upwelling zone. The average GPP is $184 \pm$ $43 \mathrm{mmol} \mathrm{O}_{2} \mathrm{~m}^{-2} \mathrm{~d}^{-1}$ in the CEP, $121 \pm 35 \mathrm{mmol} \mathrm{O}_{2} \mathrm{~m}^{-2} \mathrm{~d}^{-1}$ in the WEP, and is $147 \pm 43 \mathrm{mmol} \mathrm{O} \mathrm{O}^{-2} \mathrm{~d}^{-1}$ for PNG. Again, this $1 \sigma$ uncertainty includes contributions from gas exchange parameterization (15\%), measurement uncertainty (approximately 10\%, depends on the size of the sample), and the standard error of multiple measurements made (approximately $10 \%$, depends on the region). The standard deviation for GPP in these regions is $61 \mathrm{mmol} \mathrm{O}_{2} \mathrm{~m}^{-2} \mathrm{~d}^{-1}$ in the CEP, $83 \mathrm{mmol} \mathrm{O}_{2} \mathrm{~m}^{-2} \mathrm{~d}^{-1}$ in the WEP, and $86 \mathrm{mmol} \mathrm{O}_{2} \mathrm{~m}^{-2} \mathrm{~d}^{-1}$ in the PNG.

[29] As shown in equation (5), the measurements of dissolved gases can be combined directly in order to estimate $\mathrm{NCP} / \mathrm{GPP}$ ratios (Figure 3). In the WEP, the NCP/GPP ratios are between $2 \%$ and $8 \%$, with an average of $6 \%$. The standard deviation of the NCP/GPP ratio is $2 \%$. Using a photosynthetic quotient of 1.4 [Laws, 1991] to convert NCP in terms of $\mathrm{O}_{2}$ to $\mathrm{NCP}$ in terms of $\mathrm{C}$, and a conversion factor of 2.7 to convert from GPP to primary production as measured in ${ }^{14} \mathrm{C}$ incubation experiments [Marra, 2002], the $\mathrm{NCP} / \mathrm{GPP}$ ratio can be converted to an $f$ ratio of $11 \% \pm 3 \%$. However, comparison of ${ }^{14} \mathrm{C}$ primary productivity estimates measured on this cruise with the GPP rates show that the ratio of GPP to ${ }^{14} \mathrm{C}$ primary production in this case is highly variable and averages about 4 (see more details at end of this section). Thus, an $f$ ratio of $11 \%$ may be an underestimate. This net to gross productivity ratio is similar in the samples collected in the open ocean water in the northern part of PNG. Near the coast of Papua New Guinea, the NCP/GPP ratio is much smaller and more variable, being on average $2 \%$.

[30] We examined the relationship between NCP and GPP rates and physical and biogeochemical parameters measured on the cruise. In the WEP, weak but significant correlations existed between NCP and continuous measurements of sea surface salinity, temperature, density, gas transfer velocity, wind speed, zonal wind, and mixed layer depth (Figure 4 and Table 1). We examined different time periods over which to average the wind speed data, ranging from 1 to
20 days. The results reported here are for 6 days but correlations were similar if the averaging window was between 6 and 20 days. Much of the correlations between NCP and other parameters, however, is due to east-west gradients in NCP and these properties. Thus, we also examined correlations between linearly detrended data and found that NCP was still significantly correlated with density, salinity, temperature, and gas transfer velocity (Table 1). For PNG,

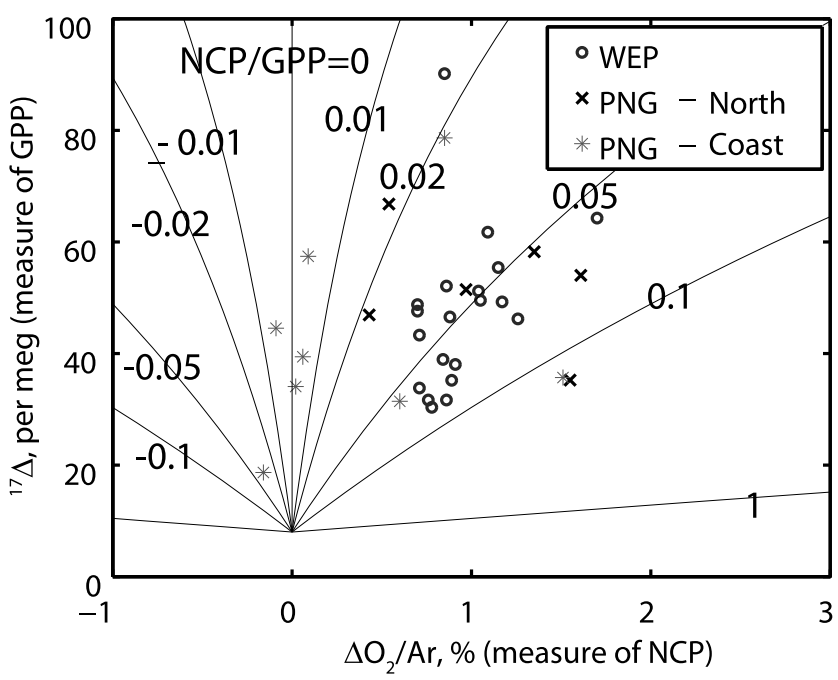

Figure 3. The ratio of $\mathrm{NCP} / \mathrm{GPP}$ can be assessed directly from $\mathrm{O}_{2} / \mathrm{Ar}$ and ${ }^{17} \Delta$ measurements, obviating the need for estimates of gas exchange. Circles on the plot represent gas measurements in the Western Equatorial Pacific (WEP), crosses represent data from the open ocean region north of Papa New Guinea, and stars represent the data along the coast of Papua New Guinea. Isolines represent lines of constant NCP/GPP ratios, as noted by the numbers. Open ocean samples have NCP/GPP ratios of $2 \%-8 \%$, corresponding to an $f$ ratio of approximately $4 \%-16 \%$. The coastal samples have much lower NCP/GPP ratios, perhaps because respiration of organic matter transported from rivers decreases NCP but not GPP. 

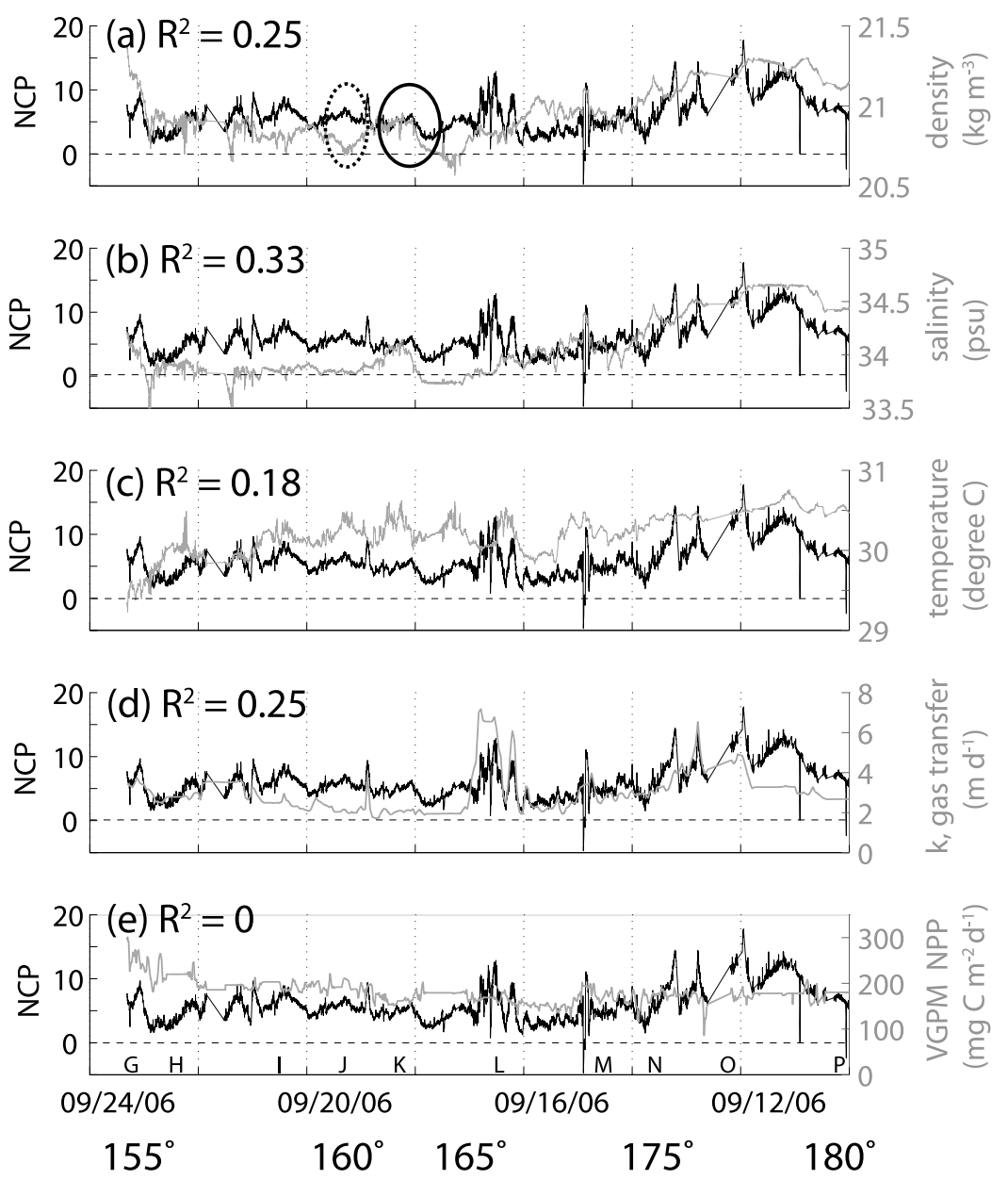

Figure 4. Net community production (black) and other properties measured continuously (gray) are plotted as a function of cruise date in the Western Equatorial region. The properties plotted are (a) density, (b) sea surface salinity, (c) sea surface temperature, (d) gas transfer velocity, and (e) net primary production (NPP) as estimated by the VGPM algorithm. The correlation coefficient $R^{2}$ between NCP and each property is recorded. In Figure 4a, there are regions (solid oval) where NCP and density are strongly positively correlated $\left(R^{2}=0.85, p=0\right)$ followed by regions (dashed oval) where NCP and density are negatively correlated $\left(R^{2}=0.55, p=0\right)$. The parameters are not plotted against longitude because the longitude is not unique during this cruise track; however, longitudes are listed in order for clarification. Additionally, the capital letters along the bottom $X$ axis correspond to the locations marked on Figure 1 .

significant correlations existed between NCP and temperature, salinity, density, and zonal wind, but not gas transfer velocity or absolute wind speed, both before and after detrending (Figure 5 and Table 1). Interestingly, there was no significant correlation in either the WEP or PNG between NCP or GPP and either SeaWiFS chlorophyll or net primary production as estimated using the VGPM algorithm of Behrenfeld and Falkowski [1997]. A lag analysis showed that including different lag times did not substantially increase the correlation coefficients.

[31] We also looked for correlations between NCP and GPP rates and the biogeochemical measurements collected during CTD casts at discrete stations. These comparisons were more limited in scope since there were only 12,11 , and 7 stations in the CEP, WEP and PNG regions, respectively. Thus, while we had continuous data sets with thousands of points, for these discrete correlations we had at most 12 data points for the comparison. We found no significant correlation between NCP or GPP and concentrations of major nutrients $\left(\mathrm{NO}_{3}, \mathrm{NO}_{2}, \mathrm{NH}_{4}, \mathrm{PO}_{4}, \mathrm{Si}\right)$ or Fe both at the surface or at depth $(75,100$, or $125 \mathrm{~m})$, primary production as determined by ${ }^{14} \mathrm{C}$ incubations $\left({ }^{14} \mathrm{C}-\mathrm{PP}\right)$, chlorophyll, or photosynthetic efficiency $\left(F_{\mathrm{v}} / F_{\mathrm{m}}\right)$ in any of the three regions. We did find weak but significant correlations between GPP and ${ }^{14} \mathrm{C}$-PP $\left(R^{2}=0.3, p=0.006\right)$ and between GPP and VGPM productivity $\left(R^{2}=0.3, p=0.004\right)$ if we examined the entire equatorial Pacific data set rather than breaking it into regions according to longitude. Though variable, we find that the ratio of GPP $/{ }^{14} \mathrm{C}$-PP is higher in the WEP $(8.2 \pm 4.0$, where uncertainty is 1 standard deviation) than it is in the CEP $(3.1 \pm 2.8)$ or PNG $(2.1 \pm 1.0)$. 
Table 1. Correlation Coefficients Between NCP Rates and Parameters for Which We Have Continuous Estimates ${ }^{\mathrm{a}}$

\begin{tabular}{lccccc}
\hline & \multicolumn{2}{c}{ WEP } & & \multicolumn{2}{c}{ PNG } \\
\cline { 2 - 3 } \cline { 5 - 6 } \multicolumn{1}{c}{ Parameters } & $R^{2}$ & \begin{tabular}{c} 
Detrended $^{\mathrm{b}}$ \\
\cline { 5 - 6 }$R^{2}$
\end{tabular} & & $R^{2}$ & $\begin{array}{c}\text { Detrended }^{\mathrm{b}} \\
R^{2}\end{array}$ \\
\hline Longitude & 0.18 & 0 & & 0.03 \\
Latitude & 0 & $(0.01)^{\mathrm{c}}$ & & 0.27 & 0.23 \\
Surface Density & 0.25 & 0.13 & & 0.24 & 0.23 \\
Surface Salinity & 0.33 & 0.22 & & $(0.29)^{\mathrm{c}}$ & $(0.25)^{\mathrm{c}}$ \\
Temperature & 0.18 & 0.05 & & 0.11 & 0.06 \\
Gas Transfer Velocity $(k)$ & 0.25 & 0.21 & & 0 & 0.04 \\
Wind Speed & 0.12 & 0.03 & & 0 & 0.01 \\
Zonal Wind & $(0.14)^{\mathrm{c}}$ & 0 & & 0.31 & 0.28 \\
Mixed Layer Depth & 0.15 & 0 & & - & - \\
SeaWiFS Chlorophyll & 0.03 & 0.01 & & - & - \\
NPP from VGPM & 0 & 0.12 & & 0 & 0 \\
\hline
\end{tabular}

${ }^{\mathrm{a}}$ Either measured continuously or calculated from satellite or float data All $p$ values were $<0.001$

${ }^{\mathrm{b}}$ Correlation coefficients calculated after linear trends were removed.

${ }^{\mathrm{c}}$ Parentheses denote negative correlations.

\section{Discussion}

\subsection{Rates of NCP and GPP in WEP}

[32] In this paper, we present NCP and GPP rates in a broad region of the equatorial Pacific, concentrating on the WEP, for which relatively little biological production data has previously been reported. The continuous nature of the NCP data allows assessment of spatial heterogeneity and the combination of NCP and GPP data yields information on how tightly the system is recycling carbon. Given the weak seasonality in the equatorial Pacific, the rates reported here probably reflect the annual average NCP and GPP though may be an underestimate since there is some suggestion that chlorophyll at least (and thus perhaps by extension production) shows some seasonality with highest values in the spring and lowest values in the fall [Strutton et al., 2008].

[33] A weak El Niño had developed by the end of the cruise, with a Multivariate Enso Index (MEI) [Wolter and Timlin, 1998] of 0.7-0.9. Turk et al. [2001] found that new production between $165^{\circ} \mathrm{E}$ and $165^{\circ} \mathrm{W}$ decreased in $\mathrm{El}$ Niño events while new production between $145^{\circ} \mathrm{E}$ and $165^{\circ}$ E increased during El Niño events. Furthermore, Strutton et al. [2008] found that at MEI > 0.2, chlorophyll concentrations decreased as MEI increased in the region
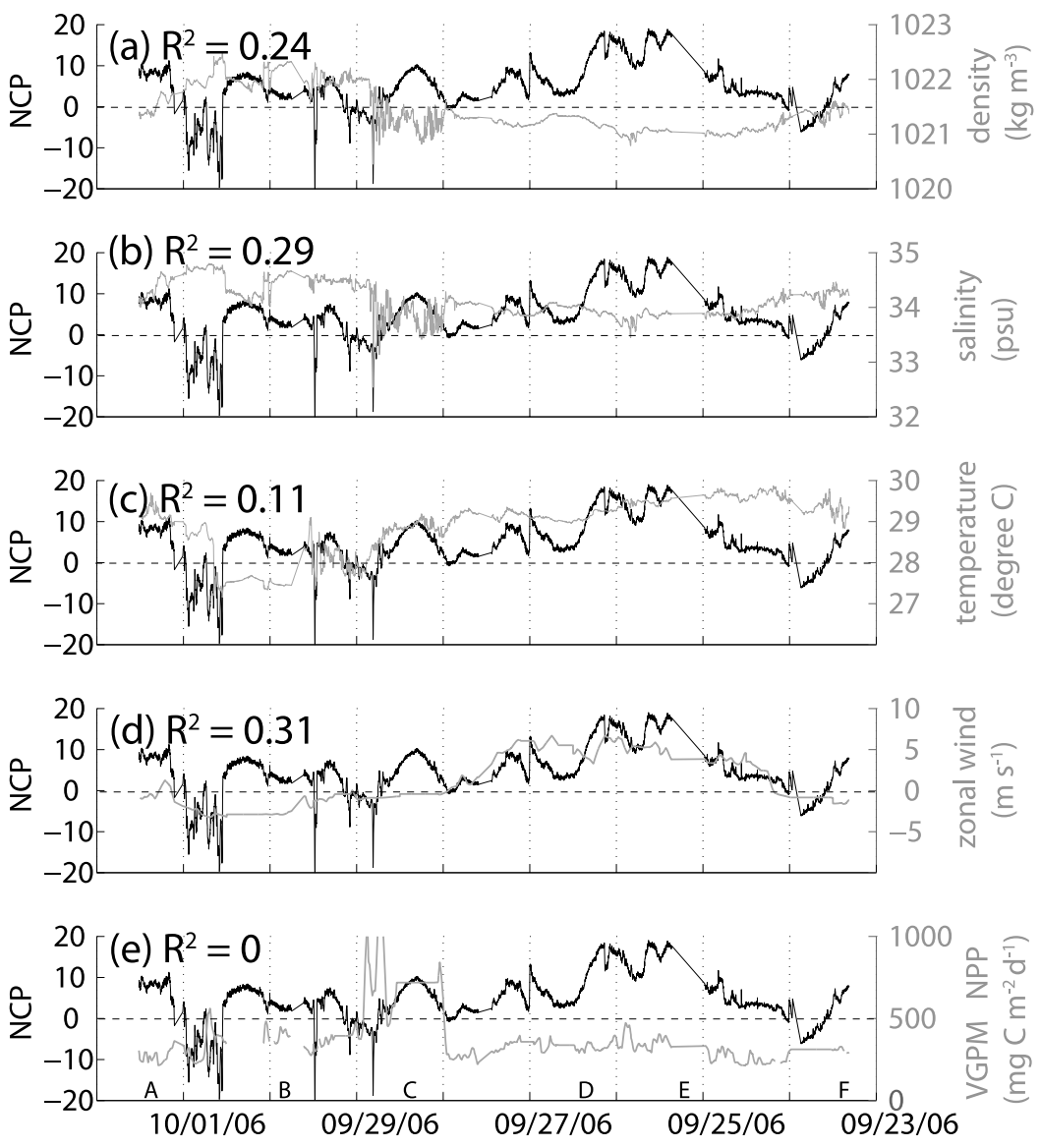

Figure 5. Similar plot as Figure 4 but for the region near Papua New Guinea. The properties plotted are NCP in all plots and (a) density, (b) sea surface salinity, (c) sea surface temperature, (d) zonal wind, and (e) net primary production as estimated by the VGPM algorithm. 
between $170^{\circ} \mathrm{W}$ and $180^{\circ}$ but at MEI $<1$, chlorophyll concentrations did not show a significant decrease with increasing MEI in the region between $125^{\circ} \mathrm{W}$ and $155^{\circ} \mathrm{W}$ (corresponding to our CEP). Thus, the NCP and GPP rates we measured in the CEP and WEP may be an underestimate of rates in a typical (i.e., non-El Niño) year, whereas the rates measured in PNG may overestimate rates in a typical year.

[34] The NCP estimates reported here are lower bounds since they assume no upward mixing of low-oxygen water. This assumption is supported by the fact that there is little vertical exchange in the western equatorial Pacific, as water of low salinity acts as a barrier between the surface and the thermocline [Lindstrom et al., 1987; Lukas and Lindstrom, 1991]. Nonetheless, we can estimate the maximum uncertainty associated with this assumption by calculating the maximum amount of $\mathrm{O}_{2}$ debt that could be mixed upward if this barrier layer were not present. To do this, we combine the concentration gradient of $\mathrm{O}_{2}$ between 100 and $300 \mathrm{~m}$ as measured in CTD profiles with a canonical estimate of vertical diffusivity coefficient $K_{\mathrm{z}}$ equal to $2 \times 10^{-5}$ [Ledwell et al., 1993; 1998]. We find that in the WEP the $\mathrm{O}_{2} / \mathrm{Ar}$ method could be underestimating $\mathrm{NCP}$ by at most $0.5 \pm$ $0.3 \mathrm{mmol} \mathrm{O}_{2} \mathrm{~m}^{-2} \mathrm{~d}^{-1}$. Future work could combine estimates of upwelling from other geochemical tracers, such as ${ }^{3} \mathrm{He}$ [Jenkins, 1988; Jenkins and Doney, 2003], with $\mathrm{O}_{2} /$ Ar measurements in order to correct for the upwelled $\mathrm{O}_{2}$ debt.

[35] We measured NCP only in the mixed layer, not the euphotic zone. In the western equatorial Pacific, the mixed layer depth is on average $30 \mathrm{~m}$ (range of 23-60 m) whereas the euphotic zone is approximately 60-90 m [Ryan et al., 2006]. Thus, if NCP was constant with respect to depth throughout the mixed layer and euphotic zone, our method would be only estimating half the euphotic depth integrated NCP. It is more likely, however, that NCP varies with depth, with NCP decreasing closer to the bottom of the euphotic zone, and thus this method underestimates total euphotic zone NCP by less than a factor of 2 . Estimates of net primary production from ${ }^{14} \mathrm{C}$ bottle incubations measured on the same cruise suggest that in the WEP mixed layer primary production accounts for $60 \% \pm 20 \%$ of total euphotic zone production (Veronica Lance, personal communication).

[36] Our geochemical tracer rate, which averages over relatively large temporal and spatial scales, falls in the middle of the range of other estimates of WEP production. Turk et al. [2001] measured new production rates by ${ }^{15} \mathrm{~N}$ uptake in bottle incubations and found 0.15-0.19 mmol N $\mathrm{m}^{-2} \mathrm{~d}^{-1}$ in regular to moderate El Niño conditions (1994 El Niño). Using the revised Redfield ratios of Anderson and Sarmiento [1994], this new production flux is equivalent to $0.4-0.5 \mathrm{~mol} \mathrm{C} \mathrm{m}^{-2} \mathrm{yr}^{-1}$. Our estimate of NCP is almost 3 times larger, which may have several causes. First, we sampled during El Niño conditions that were weaker than those prevailing when Turk sampled (MEI $=0.8$ for this cruise versus MEI $=1.4$ for Turk et al.). Second, new production may be temporally or spatially mismatched to $\mathrm{NCP}$, although the two are expected to be equal at steady state or on long temporal and large spatial scales [Eppley and Peterson, 1979]. Third, rates may vary interannually because of changes in ENSO or to other factors. Finally, there may be biases or uncertainties in the different methodologies of ${ }^{15} \mathrm{~N}$ addition in bottle experiments versus dissolved gas tracers.

[37] A much larger flux of $3.3 \mathrm{~mol} \mathrm{C} \mathrm{m}^{-2} \mathrm{yr}^{-1}$ was measured in September and October 1994, when the MEI = 1.3, by Rodier and Le Borgne [1997] who estimated the export flux using shallow drifting sediment traps at 100 and $300 \mathrm{~m}$. This flux is twice that of our measured fluxes, despite the fact that the MEI index was higher in 1994. Thus, we would have expected greater depression of production in 1994 than in 2006. The difference in our estimate and that of Rodier and Le Borgne may be due to the known problems associated with shallow sediment traps such as collection of swimmers (leading to overcollection) and hydrodynamic biases (leading to over or under collection) [Buesseler, 1991]. The discrepancy may also be due to the differences in NCP and export production, or to interannual variability.

[38] An additional relevant comparison to our results is that of Schlitzer [2004], who estimated equatorial Pacific export production from adjoint modeling of dissolved oxygen, nutrient, and carbon data. Thus, his method, like ours, is based in part on the distribution of dissolved gases. However, Schlitzer's method is not tied to any given year as he used a historical data set spanning 50 years. Schlitzer did not estimate export production specifically in the WEP; rather, he estimated export production throughout the equatorial belt to be $1.1 \mathrm{~mol} \mathrm{C} \mathrm{m}^{-2} \mathrm{yr}^{-1}$, which is in reasonable agreement with our estimate for WEP NCP of $1.5 \mathrm{~mol} \mathrm{C} \mathrm{m}^{-2} \mathrm{yr}^{-1}$. However, it is surprising that the estimate for the entire equatorial Pacific, including the central and eastern equatorial Pacific, which are more productive, is similar to our estimate for only the WEP. The agreement is also unexpected considering our measurements took place in a moderate El Niño and, therefore, may be underestimating productivity.

[39] Our NCP estimates agree reasonably well with those of production from two biogeochemical models. Model estimates of WEP export production from a global threedimensional marine ecosystem model of Moore et al. [2004] are approximately $0.5-2 \mathrm{~mol} \mathrm{C} \mathrm{m}^{-2} \mathrm{yr}^{-1}$, which compares well with our NCP estimate of $1.5 \mathrm{~mol} \mathrm{C} \mathrm{m}^{-2} \mathrm{yr}^{-1}$. However, in the Moore et al. model, export production decreases rapidly toward the west, a pattern we do not observe in our data. In a different coupled physical-biogeochemical model [Christian et al., 2002], NCP estimates in the WEP were highest during El Niño and La Niña events, ranging in those events from 3 to $9 \mathrm{~mol} \mathrm{C} \mathrm{m}^{-2} \mathrm{yr}^{-1}$. In years that were neither El Niño nor La Niña, NCP estimates ranged from 1.8 to $2.5 \mathrm{~mol} \mathrm{C} \mathrm{m}^{-2} \mathrm{y}$. This rate is slightly larger than this study's observation for a weak El Niño year.

[40] We cannot directly examine the east-west gradient in NCP given that we could not determine NCP in the CEP and eastern equatorial Pacific in this study. However, we can compare our NCP rates in the WEP to other rates measured farther east. First, the average NCP in the WEP (5.9 mmol $\mathrm{O}_{2} \mathrm{~m}^{-2} \mathrm{~d}^{-1}$, which is equivalent to $\left.1.5 \mathrm{~mol} \mathrm{C} \mathrm{m}^{-2} \mathrm{yr}^{-1}\right)$ is approximately half the NCP rate calculated using a similar approach in the eastern equatorial Pacific at longitudes $95^{\circ}$ $\mathrm{W}$ and $110^{\circ} \mathrm{W}$ by Hendricks et al. [2005]. Hendricks et al. excluded the latitude band between $2^{\circ} \mathrm{N}$ and $2^{\circ} \mathrm{S}$ (which is likely the most productive) in their calculations, as upwell- 
ing there confounds the rate estimate. Since our estimates are made farther west (east of $180^{\circ}$ ) we are able to include data near the equator. Second, the average NCP in the WEP is roughly $65 \%$ of the rate of new production measured in the central equatorial Pacific during the JGOFS study [McCarthy et al., 1996], again suggesting that NCP follows the east-west gradient in production that has been observed in chlorophyll and other indices of biological activity in the equatorial Pacific.

[41] We cannot compare our estimates of GPP in the WEP to other studies as GPP has not previously been measured in that region. However, we can compare our estimates of GPP in the CEP to two previous studies. First, during the JGOFS experiments, Bender et al. [1999] measured GPP from ${ }^{18} \mathrm{O}$ labeled bottle incubation studies at $140^{\circ} \mathrm{W}$ and $0^{\circ} \mathrm{N} / \mathrm{S}$. The method of Bender et al. is fundamentally different from the method presented here since their method reflects a shorter time scale, a more local spatial scale, and is likely to be influenced by bottle effects [Peterson, 1980]. Bender et al. found that GPP was equal to $220 \pm 6 \mathrm{mmol} \mathrm{O}_{2} \mathrm{~m}^{-2} \mathrm{~d}^{-1}$ (where uncertainty refers to 1 standard deviation) in the spring during El Niño conditions $(\mathrm{MEI}=2.2)$ and equal to $330 \pm 31 \mathrm{mmol} \mathrm{O}_{2} \mathrm{~m}^{-2} \mathrm{~d}^{-1}$ in the fall when the El Niño had weakened considerably $(\mathrm{MEI}=0.6)$. It makes the most sense to compare our estimate of GPP to the Bender et al. fall estimate given the similarity of El Niño conditions and times of year. We find that GPP is equal to $220 \mathrm{mmol} \mathrm{O}_{2}$ $\mathrm{m}^{-2} \mathrm{~d}^{-1}$ at $140^{\circ} \mathrm{W}$ and $0^{\circ} \mathrm{N} / \mathrm{S}$, which is equal to the Bender et al. spring estimate but $33 \%$ lower than the Bender et al. fall estimate. This difference may reflect the difference between the in situ and in vitro methods or may reflect interannual variability. Second, Hendricks et al. [2005], using triple oxygen isotopes, determined GPP at $95^{\circ} \mathrm{W}$ and $110^{\circ} \mathrm{W}$ (farther east than the CEP) between $8^{\circ} \mathrm{N}$ and $8^{\circ} \mathrm{S}$ but excluding the area near the equator, during November 2000 $(\mathrm{MEI}=-0.725)$ to be equal to $143 \mathrm{mmol} \mathrm{O}_{2} \mathrm{~m}^{-2} \mathrm{~d}^{-1}$. Our estimate in the CEP is considerably larger than the Hendricks et al. estimate, perhaps because of the difference in El Niño versus La Niña conditions, because Hendricks et al. excluded the region between $2^{\circ} \mathrm{N}$ and $5^{\circ} \mathrm{S}$ (probably the most productive region) from their estimate or because the Hendricks et al. estimate was made farther east where there might be smaller iron fluxes and thus smaller GPP.

[42] The $f$ ratio reported here for the WEP is $11 \% \pm 3 \%$, significantly larger than an estimate of the biogeochemically equivalent pe ratio of $3.4 \%$ as calculated using the export production algorithm of Dunne et al. [2005] in combination with an estimate of primary productivity from VGPM. However, Dunne et al. state their algorithm is only valid for pe ratios greater than $4 \%$, and even though the $f$ ratio from the data is larger than this, the pe ratio as estimated from the algorithm is below this limit. If the Dunne et al. algorithm that uses chlorophyll a is applied (rather than the algorithm that uses net primary production) in conjunction with shipboard measurements of chlorophyll $a$, then the Dunne et al. algorithm predicts negative pe ratios, a solution which is clearly unphysical.

[43] We can also compare the $f$ ratio calculated in this study to the $f$ ratio elsewhere in the Pacific. In the central and eastern equatorial Pacific, the $f$ ratio is estimated to be between 6\% and 30\% [Dugdale et al., 1992; McCarthy et al., 1996; Rodier and Le Borgne, 1997; Raimbault et al., 1999; Aufdenkampe and Murray, 2002; Hendricks et al., 2005]. Thus overall, the WEP has lower NCP, GPP, and slightly tighter recycling than its central/eastern counterpart. This may be because the WEP has smaller amounts of major nutrients. Additionally, physical instabilities, such as tropical instability waves, have been found to be associated with increased production in the central and eastern equatorial Pacific [Murray et al., 1994; Dam et al., 1995; Dunne et al., 2000] and tropical instability waves are weaker or nonexistent in the western region [Chelton et al., 2000; Eldin and Rodier, 2003]. Finally, the warmer temperatures in the western region may contribute to tighter recycling as the degradation of organic matter may occur more quickly at warmer temperatures [Laws et al., 2000; Rivkin and Legendre, 2001].

[44] The WEP has been compared to the subtropical gyres because both regions are similarly low in nutrients. The WEP NCP rates determined in this study are smaller than NCP measurements made using tracer methods in the subtropical gyres [Spitzer and Jenkins, 1989; Gruber et al., 1998; Keeling et al., 2004; Emerson et al., 2008], although some of those estimates included NCP rates in the euphotic zone rather than only in the mixed layer as our study does. The dynamics of the subtropical regions and the WEP are quite different. The subtropical gyres are characterized by downwelling whereas the WEP has weak upwelling capped by a low-salinity barrier [Lindstrom et al., 1987; Lukas and Lindstrom, 1991] that prevents most of the nutrients from reaching the sunlit surface. Additionally, the temperature of the water is warmer in the WEP than in the subtropics.

[45] Whereas the average NCP is a useful metric for comparison with other regions in the world's oceans, it is also important to consider the variability of the NCP rates. The fact that the variance-to-mean ratio approaches unity throughout much of the WEP indicates that when assessing productivity, one must take into account the heterogeneity inherent in the ocean. Were measurements of NCP only taken at traditional "stations" then several high-productivity events would have been missed. Using this subkilometer scale method for measuring NCP, we find considerable variability in NCP (Figures 1 and 4). This is counter to the observation by Le Bouteiller et al. [2003] that production, as inferred from pigment concentration, was relatively invariant during 5 day station occupations at $180^{\circ}$.

[46] Notably, the variance-to-mean ratio is smallest between $155^{\circ} \mathrm{E}$ and $165^{\circ} \mathrm{E}$. This is the only region where there are no islands near the equator. Islands may lead to increased variability in NCP either because of direct influence of terrigenous material on the carbon cycle (for example, through the input of nutrients from river runoff or slope sediments) or because the islands disrupt the equatorial undercurrent, a major source of nutrients to the surface equatorial Pacific water [Murray et al., 1995]. ADCP data collected on the cruise show that, in the region between $173^{\circ} \mathrm{E}$ and $180^{\circ} \mathrm{E}$, the equatorial undercurrent is disrupted whereas it is cohesive in the region between $155^{\circ} \mathrm{E}$ and $165^{\circ} \mathrm{E}$ (Pierre Dutrieux, personal communication). 

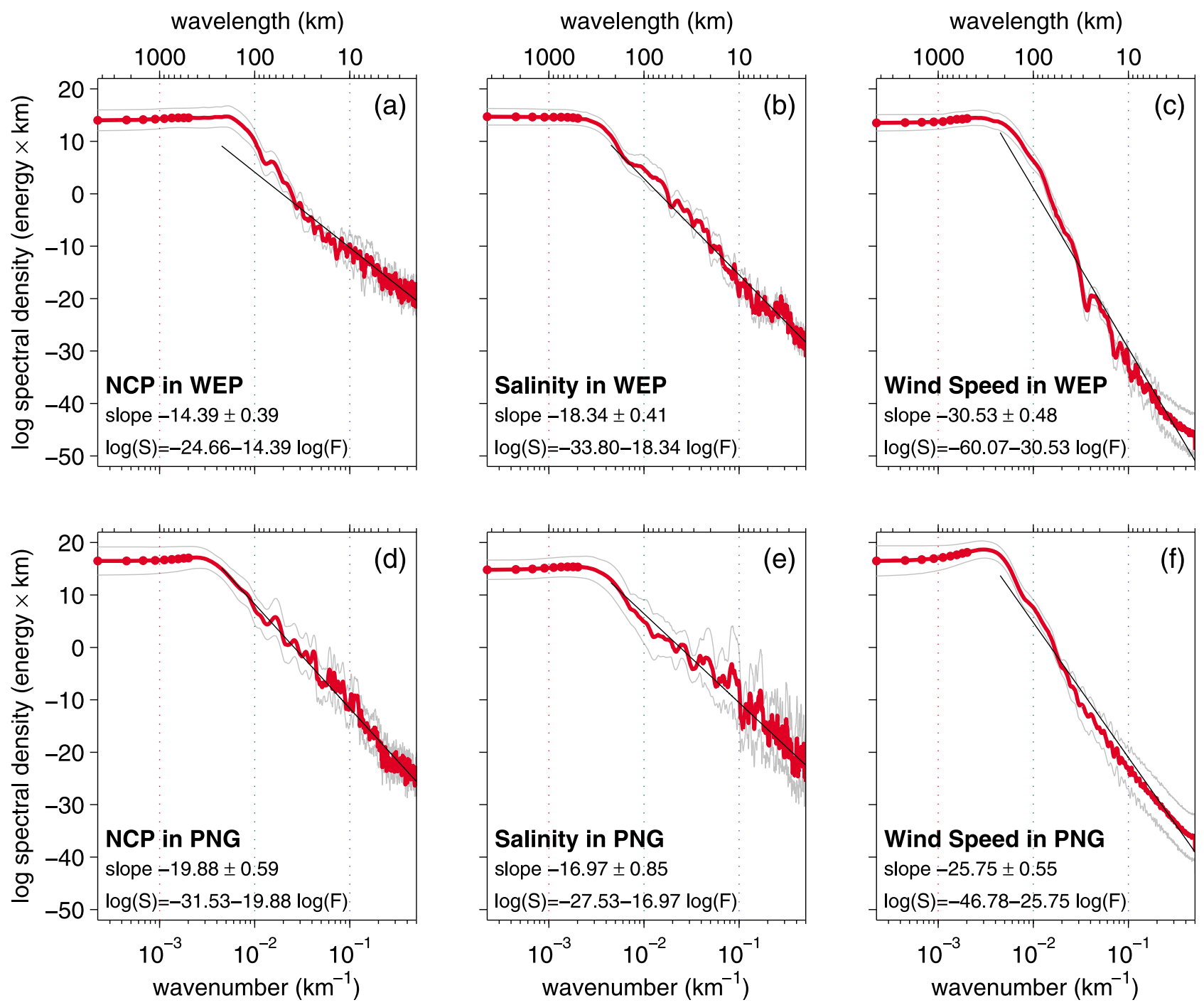

Figure 6. Logarithmic spectral density plots, as a function of distance along cruise track (in $\mathrm{km}$ ) of (a) NCP, (b) sea surface salinity, and (c) 6 day average wind speed in the western equatorial Pacific and of (d) NCP, (e) sea surface salinity, and (f) 6 day average wind speed in the region near Papua New Guinea. The curve is the logarithmic spectral density, as calculated by Welch overlapping segment analysis. The filled circles indicate frequency resolution in the low-frequency portion. The light gray curves are the $95 \%$ confidence limits as determined by jackknifed error estimates [Chave et al., 1987; Simons et al., 2000 ]. The black line is a slope fit to the spectrum corresponding to wavelengths between 1 and $200 \mathrm{~km}$. The equation for the least squares regression line and the spectral slope, with its $2 \sigma$ error, are reported.

[47] To further investigate the nature of the variability of NCP, we performed spectral analysis on the NCP data, as well as on continuous records of sea surface salinity, sea surface density, sea surface temperature, zonal wind, and average wind speed. We examined different averaging periods ranging from 1 to 20 days. The conclusions were similar if the averaging window was between 5 and 20 days, and here we report results for averaging periods of 6 days. We detrended the data and also removed the station data from the record to eliminate aliasing by extensive observations from a single location. We performed the analysis as a function of distance along cruise track, rather than as time, so that the physical interpretation would be more obvious. We calculated the spectral density by Welch overlapping segment analysis on $70 \%$ overlapping segments of $500 \mathrm{~km}$ length. One prolate-spheroidal taper with a time bandwidth product $\mathrm{NW}=4$ was used per segment. The estimates are robust [Chave et al., 1987; Simons et al., 2000], and 95\% confidence intervals were determined from jackknifed error estimates.

[48] In the WEP, plots of the spectral density (Figures 6a, $6 \mathrm{~b}$, and $6 \mathrm{c}$ ) illustrate that NCP, salinity, and wind speed all have red spectra with no obvious peaks, suggesting there is no single oscillating process driving the variations. The 
spectral density plots for density and to a lesser extent temperature are similar to that of salinity and therefore are not shown. The time series of all properties are weakly, if at all, nonstationary. In the WEP, NCP, wind speed, and salinity show distinctly different spectra. First, the linear range of the power spectrum extends from roughly 1 to $20 \mathrm{~km}$ for NCP and wind speed whereas it extends from roughly 1 to $200 \mathrm{~km}$ for salinity. Additionally, the values of the spectral slopes are significantly different. These differences suggest that the mechanisms that are causing variability in NCP are in a large part different than the ones causing variability in density, salinity, temperature, and perhaps wind speed.

[49] A rough measure of length scale of correlation can be determined from calculating the $e$-folding length of the autocorrelation function for NCP, temperature, density, and salinity. For NCP, this correlation length scale is about $50 \mathrm{~km}$. For salinity and density, the correlation length scale is about $130 \mathrm{~km}$. For temperature, the correlation length scale is about $100 \mathrm{~km}$ and for wind speed the correlation length scale is $170 \mathrm{~km}$. The correlation length scale of $100-130 \mathrm{~km}$ is on the same order as that for deep convective rain systems in the warm tropical Pacific [Masunaga et al., 2005]. The correlation length scale of NCP and the physical properties all fall within the range of length scale of eddies, which is 50 $500 \mathrm{~km}$. The correlation length scales are all much shorter than the roughly $1000 \mathrm{~km}$ length scales of tropical instability waves or Kelvin waves and orders of magnitude longer than the roughly 30-50 m length scale of Langmuir cells in the WEP. The difference in correlation length scales between $\mathrm{NCP}$ and the physical properties suggests that there may be fundamentally different processes controlling the distribution of NCP than are controlling the distribution of salinity, density, or temperature.

[50] Futhermore, coherence analysis, which assesses whether there are similar spectral properties (and thus perhaps common causes of variability) in different data sets, shows there is no strong coherence between NCP and salinity (Figure 7a), temperature, density, or zonal wind, whereas there was strong coherence (typically $0.6<\gamma^{2}<0.8$ at most wavelengths) between salinity and density (Figure $7 b$ ). Of course, salinity is a fundamental control on density so it is not surprising that the two are coherent at all wavelengths. There is strong coherence $\left(\gamma^{2} \sim 0.5\right)$ between NCP and average wind speed at wavelengths between 100 and $200 \mathrm{~km}$ (Figure 7c). Notably, the strong coherence between NCP and the average wind speed only occurs in a narrow range of wavelengths $(100-200 \mathrm{~km})$ whereas the coherence between salinity and density occurs over a range of wavelengths. When different averaging windows for wind speed were chosen (5-20 days), the strong coherence at approximately 100-200 km persists. This suggests that there may be a fundamental link between variability in wind speed and in NCP in the equatorial Pacific, as has been suggested by Strutton et al. [2008].

\subsection{Correlations in the WEP}

[51] Although spectral analysis suggests that the causes for much of the variability are different for NCP than for the physical processes, correlations between NCP and sea surface density, salinity, and temperature (Figures $4 a-4 c$ ) sug- gest that there may be, in part, a physical forcing to NCP. One can see intervals along the cruise track where a strong positive correlation of density and NCP is followed by a strong negative correlation (circled regions in Figure 4a). This may be a result of the complicated response of the tracer system to vertical mixing. An increase in vertical mixing, e.g., caused by increased winds, would result in an injection of dense, colder, fresher water. Such vertical mixing would also bring up nutrients, stimulating production and thus would be seen as an increase in NCP. However, the injection might also bring up an oxygen debt which would appear as a decrease in NCP given the limitations of this method. The ratio of nutrient concentration to oxygen debt may vary as $\mathrm{C} / \mathrm{N}$ and $\mathrm{C} / \mathrm{P}$ ratios have been shown to vary in space and time [Anderson and Pondaven, 2003]. If the water being transported to the mixed layer has a larger nutrient concentration than oxygen debt, then the nutrients could spur biological production and produce $\mathrm{O}_{2}$ in an amount that overcomes the $\mathrm{O}_{2}$ debt, and $\Delta \mathrm{O}_{2} / \mathrm{Ar}$ and thus our estimate of NCP would increase, resulting in a positive correlation. Other possibilities for the positive and negative correlations include differing response of biological production to different types of horizontal fronts, potential time lags between physical changes and biological response, or differing averaging times of the methods to measure the physical properties (near instantaneous) and to measure NCP (averaging of 1-2 weeks).

[52] The correlations between NCP and zonal wind, wind speed, and gas transfer velocity (Figure 4d) support the suggestion that in the WEP, wind forcing is an important control on NCP [Strutton et al., 2008]. However, only the correlation with gas transfer velocity remains after detrending the data. This may be because the gas transfer velocity is the more relevant parameter since it is the weighted average of the wind speed over the prior several weeks (see section 2.2 and Reuer et al. [2007]) whereas the wind speed is a simple 5 day average of wind speed (results were similar if other time periods for averaging wind speed were used). Another difference is that the gas transfer velocity is proportional to the square of the wind speed, but this alone is not enough to explain the stronger correlation with gas transfer velocity since the correlation of NCP with the square of the wind speed has $R^{2}=0.15$ before detrending and $R^{2}=0.04$ after, both significantly weaker correlations than that of NCP and gas transfer velocity.

[53] Surprisingly, no correlations were found in the WEP between the NCP or GPP rates and estimates of chlorophyll $a$ from satellites or net primary production (NPP) as estimated from the VGPM algorithm (Figure 4e) in the WEP. The satellite data yields estimates of NPP, our gas measurements yield information on NCP and GPP, and we would expect a correlation between these properties. The lack of correlation between satellite data and the NCP rates is disturbing since satellite estimates are often used to form hypotheses about biological production and carbon cycling. However, it is true that NCP, NPP, and GPP are all assessing different aspects of biological production. GPP is the gross photosynthetic flux. NPP is photosynthesis minus autotrophic respiration, whereas NCP is photosynthesis minus autotrophic and heterotrophic respiration. Thus, the 

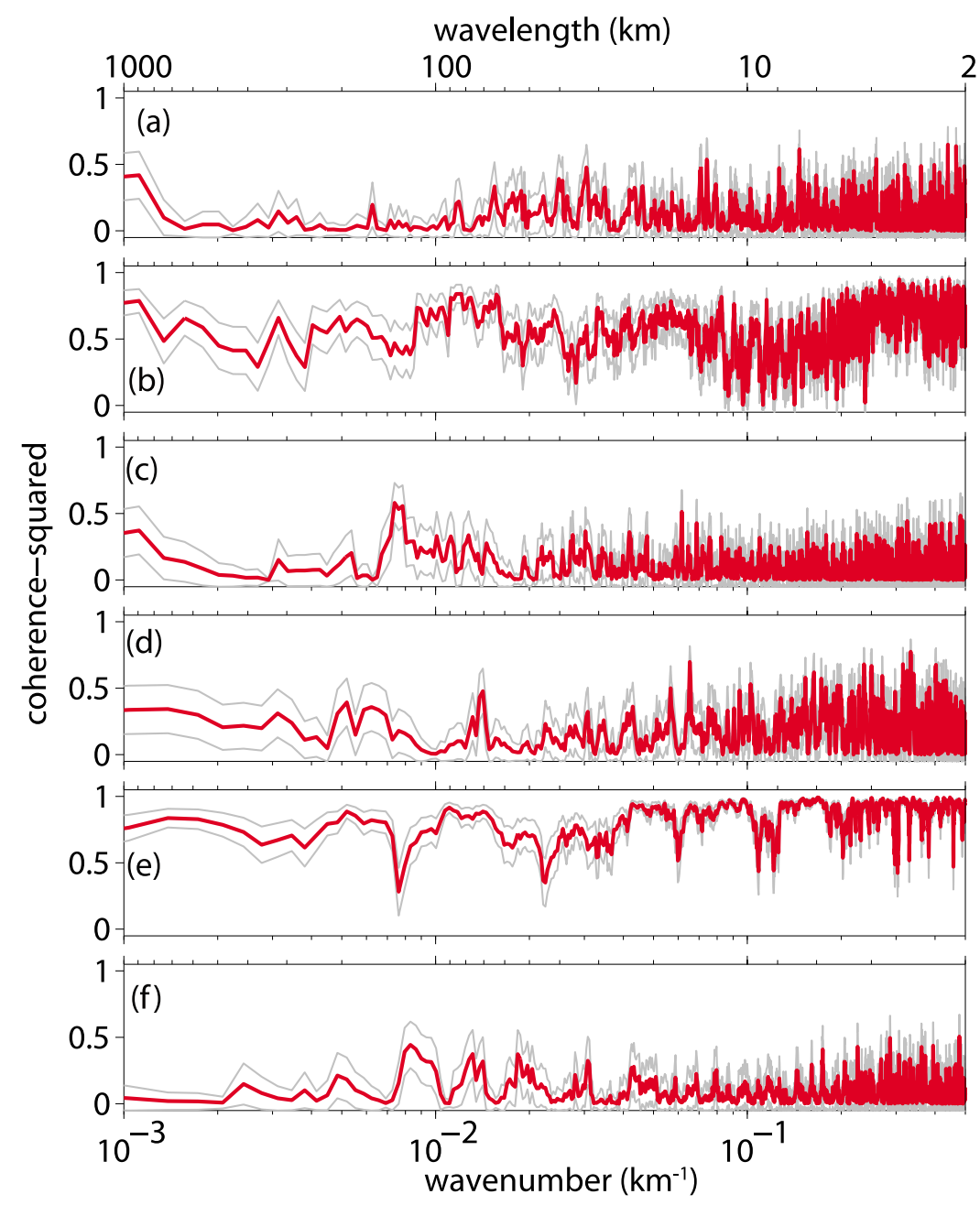

Figure 7. Square of the coherence, as a function of reciprocal distance along the cruise track $\left(\mathrm{km}^{-1}\right)$ of (a) NCP and sea surface salinity, (b) sea surface salinity and sea surface density, and (c) NCP and 6 day averaged wind speeds, all in the western equatorial Pacific and (d) NCP and sea surface salinity, (e) sea surface salinity and density, and (f) NCP and 6 day averaged wind speeds, all in the region near Papua New Guinea. Light gray curves are the $95 \%$ confidence limits of the square of the coherence as determined by jackknifed error estimates [Chave et al., 1987; Simons et al., 2000].

lack of correlation between satellite-derived NPP and gas tracer-derived NCP and GPP may be a reflection of the differences in spatial and temporal scales of the methods or a reflection of the differences in variability of photosynthesis, autotrophic, and heterotrophic respiration. Furthermore, while fluxes of GPP from triple oxygen isotopes and NPP from VGPM were not correlated within the WEP itself, we did find a significant correlation between NPP from VGPM and GPP $\left(R^{2}=0.32, p=0.004\right)$ if we used the data from the entire equatorial region covered by this study (i. e., used all the data points on Figure 2). Both the VGPM algorithm and our GPP measurements predict higher biological productivity in the CEP than in the WEP, and it is this broad-scale pattern that leads to the correlation.

[54] Additionally, no correlations were found in the comparison of NCP and GPP rates in the WEP to the biogeochemical parameters collected at the stations (con- centrations of nitrate, phosphate, silicate, and iron at the surface and at depth; photosynthetic efficiency $F_{\mathrm{v}} / F_{\mathrm{m}}$; chlorophyll concentrations; ${ }^{14} \mathrm{C}$ primary productivity). The lack of correlation with discrete properties measured at stations may be because of the difference in temporal scale of the measurements. For example, nutrient concentrations reflect the state of the ocean at the moment the measurement is taken whereas the NCP and GPP measurements average over the time scale of exchange of the gases, approximately the previous 2 weeks. Alternatively, it could be because the standard set of parameters believed to influence biological production is not truly the driving force behind production in the western equatorial Pacific. Other work has also shown a lack of correlation between surface nutrients and production in the western equatorial Pacific [Rodier and Le Borgne, 1997]. It is unclear why NCP is not correlated with chlorophyll, photosynthetic efficiency, ${ }^{14} \mathrm{C}$ primary 
productivity, nutrient concentration at depth $(75,100$, or $125 \mathrm{~m}$ ) or depth of the $20^{\circ}$ isotherm.

$[55]{ }^{14} \mathrm{C}$ primary productivity is likely a measure of productivity between NPP and GPP [Marra, 2002]. A lack of correlation between the ${ }^{14} \mathrm{C}-\mathrm{PP}$ and GPP in the WEP may reflect the difference in time scales of the methods and/or may be a result of variability in autotrophic respiration. We do see a correlation between ${ }^{14} \mathrm{C}$-PP and GPP if we consider all the data in the equatorial Pacific, suggesting that both ${ }^{14} \mathrm{C}$-PP and GPP may be registering the same large-scale differences in the regions but are not responding to the small-scale variability in the same way. Researchers sometimes assume GPP is directly related to ${ }^{14} \mathrm{C}-\mathrm{PP}$, often using a factor of 2.7 to convert between the two [Marra, 2002]. However, more recently, Luz et al. [2009] found that in the Sargasso Sea the GPP $/{ }^{14} \mathrm{C}-\mathrm{PP}$ ratio changed throughout the year, ranging from 3.5 to 7.9. The lack of correlation we observe here suggests there can be spatial as well as temporal differences in the GPP $/{ }^{14} \mathrm{C}-\mathrm{PP}$ ratio. Indeed, we see such differences on larger scales, as the ratio of GPP $/{ }^{14} \mathrm{C}-\mathrm{PP}$ is higher in the WEP than it is in the CEP or PNG.

\subsection{Rates of NCP and GPP in the PNG Region}

[56] Both the highest and the lowest values of NCP found in the equatorial region (outside of the CEP where the apparent low values are actually due to upwelling) are measured in the PNG region. Rates of GPP at one of the stations near the coast are moderately high, similar to rates in the CEP, whereas rates at the other coastal stations are on the low side, similar to rates in the WEP. Negative values of NCP are found near the mouth of the Sepik River, marked by a red star in Figure 1b. The Sepik River is known to contribute significant loads of organic matter, sediments, and nutrients to the coastal waters [Burns et al., 2008]. The negative NCP values are consistent with net heterotrophy, due possibly to remineralization of organic matter input by the river. Additionally, sediment plumes from the Sepik river may be shading phytoplankton, decreasing productivity. This shading hypothesis is consistent with the low GPP rate calculated at the mouth of the Sepik river as compared to the higher GPP rate calculated slightly south of the river. Although coastal upwelling could cause negative values, such upwelling is unlikely in September since upwelling along this northeastern coast of Papua New Guinea predominantly occurs in December through March during the Northwest monsoon [Fine et al., 1994; Cresswell, 2000]. Moreover, no shoaling of pycnoclines was observed at the time of sampling.

[57] Similarly, the negative values of NCP ( $-20 \mathrm{mmol}$ $\mathrm{O}_{2} \mathrm{~m}^{-2} \mathrm{~d}^{-1}$ ) found in the area just to the northeast of the Vitiaz Strait are probably not attributable to coastal upwelling. Surface currents bring waters from the Vitiaz straits to the northwest [Fine et al., 1994], and thus, these low values in the eastern Bismarck Sea should not be the result of $\mathrm{O}_{2}$ depleted waters being transported from the south. Additionally, these negative values are not near the output of any river. Thus the only remaining explanation for the negative NCP in these waters is local net heterotrophy, but more work should be done to confirm this hypothesis.
[58] Some of the highest values of NCP found in this study occur in the open ocean to the north of PNG. There are two maxima of NCP, occurring at the same time as wind bursts, which occur between stations and would have been missed by traditional sampling methods. In part, because of the response to these storm events, NCP is correlated with zonal wind in the PNG region. Westerly wind bursts can puncture the barrier layer [Lukas and Lindstrom, 1991], bringing up nutrients to the surface that may be fueling NCP. This is supported by the negative correlation between NCP and salinity we found in this region (Table 1 and Figure $5 \mathrm{~b}$ ), since the waters below the barrier layer will have higher salinity.

[59] Spectral density plots of NCP (Figure 6d) as well as of physical properties such as sea surface salinity (Figure 6e), sea surface density (not shown), sea surface temperature (not shown), average wind speed (Figure 6f), and zonal winds (not shown) in the PNG region all show red spectra with no obvious peaks. The linear range of the spectral density plots for NCP, salinity, temperature, and density extend from 1 to $200 \mathrm{~km}$ whereas for wind speed extends from 1 to $30 \mathrm{~km}$. The similarity in the spectral densities suggest that unlike in the WEP, it is plausible that the spectrum for NCP here is statistically similar to that of salinity, density, and temperature, suggesting a single mechanism may be controlling the distribution of all these properties. However, the general absence of coherence between NCP and salinity (see below) is an indicator that salinity does not directly control NCP. The linear range and slopes are significantly different for wind speed than for NCP.

[60] NCP, salinity, temperature, and density all have similar second order statistics. The length scales of autocorrelation are similar for all the properties as well as for wind speed. Specifically, the $e$-folding correlation length scale is $70 \mathrm{~km}$ for NCP, $80 \mathrm{~km}$ for salinity, $90 \mathrm{~km}$ for density, $96 \mathrm{~km}$ for temperature, and $69 \mathrm{~km}$ for wind speed. This length scale is on the same order as that for the rain correlation length scale for deep convective systems [Masunaga et al., 2005] and as of eddies. As in the WEP, coherence analysis showed that there was no strong relationship between NCP and salinity (Figure 7d), temperature, or density, whereas there was a strong coherence between density and salinity (Figure 7e). There is significant coherence between NCP and wind speed at wavelengths of 100 $150 \mathrm{~km}$, suggesting that as in the WEP, there may be a fundamental link between wind speed and NCP.

[61] There are no significant correlations between NCP and nutrients or other biogeochemical parameters measured at the stations. Again, this may suggest a real lack of relationship between the parameters or may be a result of difference in temporal time scales of the measurements.

\section{Conclusions}

[62] We have presented a detailed characterization of NCP and GPP in the western equatorial Pacific and in the coastal region near Papua New Guinea, as well as measurements of GPP only in the central equatorial Pacific. The average NCP in the western equatorial Pacific was 


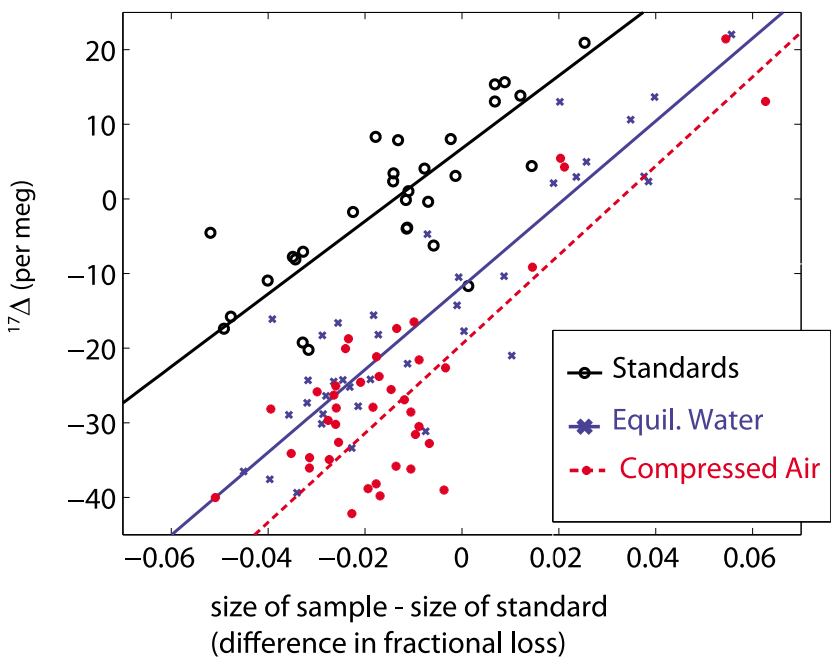

Figure A1. The measured ${ }^{17} \Delta$ for gas standards (a laboratory made standard consisting of a mixture of $\mathrm{O}_{2}$ and $\mathrm{Ar}$ gas) (black circle), equilibrated laboratory waters (blue cross) not yet calculated relative to the compressed air standard, and compressed air samples (red solid circle) as a function of the difference in amount of gas in the sample and standard bellows. This difference is expressed quantitatively as the fractional decrease in mass 32 between the beginning and end of the first analysis block in the sample side and in the standard side (see equation (A1)). The ${ }^{17} \Delta$ measurements have been corrected for pressure imbalance and nitrogen and argon effects. The lines represent type 1 least squares linear regressions, with equations for the standards: ${ }^{17} \Delta=6.8( \pm 2)+487( \pm 40) \times$ size difference; for the equilibrated waters: ${ }^{17} \Delta=-11.8( \pm 1)+555( \pm 40) \times$ size difference; and for the compressed airs: ${ }^{17} \Delta=-19.5( \pm 3)+$ $597( \pm 104) \times$ size difference.

$5.9 \pm 0.9 \mathrm{mmol} \mathrm{O}_{2} \mathrm{~m}^{-2} \mathrm{~d}^{-1}$. There is substantial variability in the NCP rates, as illustrated by the standard deviation of the NCP rates in the western equatorial Pacific being $2.6 \mathrm{mmol}$ $\mathrm{O}_{2} \mathrm{~m}^{-2} \mathrm{~d}^{-1}$, equal to almost half of the average NCP. The average NCP in the region near Papua New Guinea was $4.8 \pm$ $0.6 \mathrm{mmol} \mathrm{O} \mathrm{m}^{-2} \mathrm{~d}^{-1}$ with even more heterogeneity shown by a standard deviation of $6.0 \mathrm{mmol} \mathrm{O}_{2} \mathrm{~m}^{-2} \mathrm{~d}^{-1}$. We have found that NCP rates in the western equatorial Pacific are roughly half the magnitude of rates in the better studied central equatorial Pacific. Rates of NCP are weakly but significantly correlated with physical parameters, such as salinity, temperature, and density, suggesting a link with physical transport. Rates of NCP show no significant correlation with satellite chlorophyll or satellite based primary production estimates for this region.

[63] The net to gross production in the western equatorial Pacific is $6 \%$, which is slightly smaller than the ratio in the central equatorial Pacific. We determined the rate of gross primary production to be equal to $184 \pm 41 \mathrm{mmol} \mathrm{O}_{2} \mathrm{~m}^{-2}$ $\mathrm{d}^{-1}$ in the central equatorial Pacific, $121 \pm 34 \mathrm{mmol} \mathrm{O}_{2} \mathrm{~m}^{-2}$ $\mathrm{d}^{-1}$ in the western equatorial Pacific, and $147 \pm 41 \mathrm{mmol} \mathrm{O}_{2}$ $\mathrm{m}^{-2} \mathrm{~d}^{-1}$ in the region near Papua New Guinea. Rates of GPP within each of the above regions do not show any correlation with satellite-based primary production estimates, but there is a significant correlation between GPP and the VGPM NPP estimate if all the data throughout the equatorial Pacific is included. Thus, the satellite estimates seem to be able to capture the large-scale spatial patterns of GPP but not the detailed structure.

[64] Future work should include investigating the data with biogeochemical models. The wealth of NCP data presented here may provide valuable constraints on biogeochemical models and the models, in turn, may be able to elucidate reasons behind the variability in the data.

\section{Appendix A: The ${ }^{17} \Delta$ of Equilibrated Water}

[65] There is some disagreement in the literature as to what is the appropriate value for ${ }^{17} \Delta$ of equilibrated water $\left({ }^{17} \Delta_{\text {eq }}\right.$ as listed in equations (4) and (5)). Researchers use ${ }^{17} \Delta_{\mathrm{eq}}=16$ [Luz and Barkan, 2000; Juranek and Quay, $2005],{ }^{17} \Delta_{\mathrm{eq}}=18$ [Sarma et al., 2006], ${ }^{17} \Delta_{\mathrm{eq}}=8$ [Reuer et al., 2007], or calculate ${ }^{17} \Delta_{\mathrm{eq}}$ as a function of temperature [Luz and Barkan, 2009]. In Appendix A, we describe how we determined ${ }^{17} \Delta_{\text {eq }}$ to be equal to 8 and also a correction to ${ }^{17} \Delta$ measurements that must be made for differences in the amount of gas in the sample and standard side bellows of the mass spectrometer.

[66] A $4 \mathrm{~L}$ beaker of distilled water, poisoned with $0.02 \%$ $\mathrm{HgCl}_{2}$, was stirred in the laboratory for at least $48 \mathrm{~h}$. The value of ${ }^{17} \Delta_{\text {eq }}$ does not seem to depend on the method used for equilibrating the water (i.e., stirring versus bubbling) as both Juranek and Quay [2005] and Reuer et al. [2007] used the same method of stirring water and yet measured different values of ${ }^{17} \Delta_{\text {eq }}$ Furthermore, Juranek and Quay [2005] and Luz and Barkan [2000] measured the same value of ${ }^{17} \Delta_{\text {eq }}$ despite Juranek and Quay [2005] using stirring and Luz and Barkan [2000] using bubbling as methods for equilibration.

[67] Equilibrated water samples were drawn through tygon tubing from the beaker into preevacuated glass bottles [Emerson et al., 1995]. The samples were analyzed using methods described by Hendricks et al. [2005] and Reuer et al. [2007] on a Finnigan MAT 252 isotope ratio mass spectrometer. The average of 16 equilibrated water samples, measured during the same period as the samples from this cruise were run (approximately one sample every other day), was $9 \pm 2(1 \sigma$ standard error).

[68] A second way to determine the value for equilibrated water samples is related to a correction for the difference in amount of gas in the standard and sample side bellows. Experiments show that the measured ${ }^{17} \Delta$ of samples is dependent on the relative amount of gas in the sample side of the bellows compared to the amount of gas in the standard side of the bellows, even if the pressure in the two sides is initially balanced (Figure A1). In order to correct for this effect, experiments were performed where different amounts of the same standard (composed of approximately $95 \% \mathrm{O}_{2}$ and $5 \% \mathrm{Ar}$ ) were inlet into the sample and standard bellows, the pressure was balanced, and then the ${ }^{17} \Delta$ was determined. As a quantitative metric for sample size, we use the 


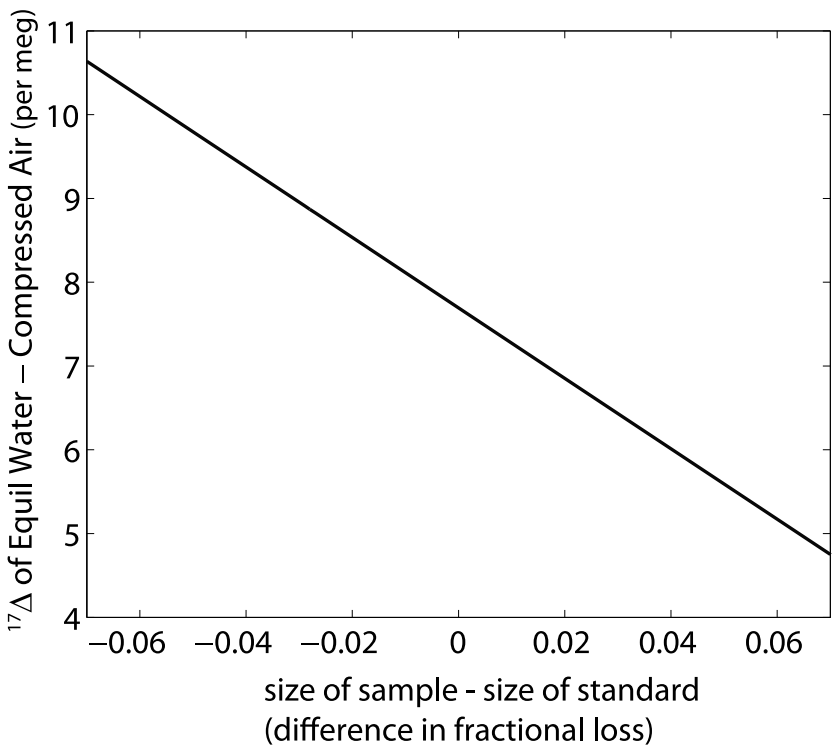

Figure A2. The difference in ${ }^{17} \Delta$ between equilibrated water samples, not yet calculated relative to the compressed air standard, and compressed air samples, calculated from the linear fits to the data in Figure A1, as a function of the difference in amount of gas in sample and standard bellows. When the amount of gas is the same in the sample and standards size, the difference in ${ }^{17} \Delta$ between equilibrated water and compressed air samples is $7.7 \pm 3$ per meg. All ${ }^{17} \Delta$ have been corrected for pressure imbalance and nitrogen and argon effects.

fractional drop in voltage of mass 32 between the beginning and end of the first analysis block, i.e.,

$$
\text { size }=\frac{\mathrm{V} 32_{\mathrm{i}}-\mathrm{V} 32_{\mathrm{f}}}{\mathrm{V} 32_{\mathrm{i}}}
$$

where $\mathrm{V} 32_{\mathrm{i}}$ is the voltage of mass 32 measured at the beginning of the first analysis block (which consists of 24 cycles with a $26 \mathrm{~s}$ integration time) and $\mathrm{V} 32_{\mathrm{f}}$ is the voltage of mass 32 measured at the end of the first analysis block. The measured ${ }^{17} \Delta$ was a linear function of the size of the sample $\left(R^{2}=0.83\right)$ (black circles in Figure 1); if the sample side had less gas (more) than the standard side, then the measured ${ }^{17} \Delta$ would be higher (lower). We hypothesize this effect may be due to the fact that although the pressure starts balanced between the standard and sample side, if there is less gas in the bellows one side, the pressure drops more quickly on that side, leading to imbalances by the end of the analysis block. This difference in pressure by the end of the analysis block is not corrected for in the typical pressure imbalance correction since the latter refers to pressure imbalance at the start of the analysis block.

[69] The correction appears stable with time. This size effect may not occur in all IRMS. Retroactive analysis of equilibrated waters and compressed airs measured using a different MAT 252 IRMS does not seem to show the same affect; however, there was not a wide range in size in the previous water and air samples and purposeful experiments were never done so it is not certain whether that IRMS showed a size effect or not.

[70] Samples of equilibrated waters and compressed air also show this size dependency (blue and red curves in Figure A1). Additionally, the difference in ${ }^{17} \Delta$ between the equilibrated water samples and the compressed air samples, calculated by subtracting the linear fits (type I regression) for water and air samples, is a function of size (Figure A2), potentially confounding previous attempts to determine the

${ }^{17} \Delta$ value of equilibrated water. The difference in ${ }^{17} \Delta$ between the equilibrated water samples and the compressed air samples when the sizes are balanced is $7.7 \pm 3$ ( $1 \sigma$ error) per meg, confirming a previous report of a ${ }^{17} \Delta$ value for equilibrated water of 8 per meg [Reuer et al., 2006] but disagreeing with suggestions of a ${ }^{17} \Delta$ value for equilibrated water of 16 per meg [Luz and Barkan, 2000; Juranek and Quay, 2005] or 18 per meg [Sarma et al., 2006].

[71] Acknowledgments. We sincerely thank Jim Murray, chief scientist of the EUC-Fe cruise, for organizing this program and encouraging and supporting our efforts. We are grateful to Pierre Dutrieux, Anne Johansen, Zackary Johnson, Veronica Lance, Lindsey Shank, Lia Slemons, and Wendy Guo for their willingness to share data. We thank the captain and crew of the $R / V$ Kilo Moana. We thank Gustavo Goni for the mixed layer depth data as derived from ARGO floats. We gratefully acknowledge many fruitful discussions with Anne Johansen and her thoughtful comments on drafts of this manuscript. We thank Frederik Simons for his help in the spectral analysis and are grateful for the use of the Matlab functions posted on his website at http://www.frederik.net. This paper was improved thanks to the helpful suggestions of two anonymous reviewers. This work was supported by the NSF Chemical Oceanography and the Office of Polar Programs, by the NOAA climate and global change program (fellowship to RHRS), and by Princeton University (Hess fellowship to RHRS).

\section{References}

Anderson, L. A., and J. L. Sarmiento (1994), Redfield ratios of remineralization determined by nutrient data-analysis, Global Biogeochem. Cycles, 8(1), 65-80.

Anderson, T. R., and P. Pondaven (2003), Non-redfield carbon and nitrogen cycling in the Sargasso Sea: pelagic imbalances and export flux, Deep-Sea Res., Part I, 50(5), 573-591.

Armstrong, F. A., C. R. Stearns, and J. D. H. Strickland (1967), Measurement of upwelling and subsequent biological processes by means of technicon autoanalyzer and associated equipment, Deep-Sea Res., 14(3), 381-\&.

Aufdenkampe, A. K., and J. W. Murray (2002), Controls on new production: the role of iron and physical processes, Deep-Sea Res., Part II, 49(13-14), 2649-2668.

Behrenfeld, M. J., and P. G. Falkowski (1997), Photosynthetic rates derived from satellite-based chlorophyll concentration, Limnol. Oceanogr., 42(1), 1-20.

Behrenfeld, M. J., K. Worthington, R. M. Sherrell, F. P. Chavez, P. Strutton, M. McPhaden, and D. M. Shea (2006), Controls on tropical Pacific Ocean productivity revealed through nutrient stress diagnostics, Nature, 442(7106), 1025-1028.

Bender, M., J. Orchardo, M. L. Dickson, R. Barber, and S. Lindley (1999), In vitro O-2 fluxes compared with $\mathrm{C}-14$ production and other rate terms during the JGOFS Equatorial Pacific experiment, Deep-Sea Res., Part I, 46(4), 637-654.

Blanchot, J., J. M. Andre, C. Navarette, J. Neveux, and M. H. Radenac (2001), Picophytoplankton in the equatorial Pacific: Vertical distributions in the warm pool and in the high nutrient low chlorophyll conditions, Deep-Sea Res., Part I, 48(1), 297-314.

Buesseler, K. O. (1991), Do upper-ocean sediment traps provide an accurate record of particle flux?, Nature, 353, 420-423.

Burns, K. A., G. Brunskill, D. Brinkman, and I. Zagorskis (2008), Organic carbon and nutrient fluxes to the coastal zone from the Sepik River outflow, Cont. Shelf Res., 28(2), 283-301.

Cassar, N., B. A. Barnett, M. L. Bender, J. Kaiser, R. C. Hamme, and B. Tilbrook (2009), Continuous high-frequency dissolved O-2/Ar mea- 
surements by equilibrator inlet mass spectrometry, Anal. Chem., 81(5), $1855-1864$.

Chai, F., R. C. Dugdale, T. H. Peng, F. P. Wilkerson, and R. T. Barber (2002), One-dimensional ecosystem model of the equatorial Pacific upwelling system: Part I. Model development and silicon and nitrogen cycle, Deep-Sea Res., Part I, 49(13-14), 2713-2745.

Chai, F., M. S. Jiang, Y. Chao, R. C. Dugdale, F. Chavez, and R. T. Barber (2007), Modeling responses of diatom productivity and biogenic silica export to iron enrichment in the equatorial Pacific Ocean, Global Biogeochem. Cycles, 21(3), GB3S90, doi:10.1029/2006GB002804.

Chave, A. D., D. J. Thomson, and M. E. Ander (1987), On the robust estimation of power spectra, coherences, and transfer-functions, J. Geophys. Res, 92(B1), 633-648.

Chavez, F. P., and R. T. Barber (1987), An estimate of new production in the equatorial Pacific, Deep-Sea Res., Part 1, 34(7), 1229-1243.

Chelton, D. B., F. J. Wentz, C. L. Gentemann, R. A. de Szoeke, and M. G Schlax (2000), Satellite microwave SST observations of transequatorial tropical instability waves, Geophys. Res. Lett., 27(9), 1239-1242.

Christian, J. R., M. A. Verschell, R. Murtugudde, A. J. Busalacchi, and C. R. McClain (2002), Biogeochemical modeling of the tropical Pacific Ocean: I. Seasonal and interannual variability, Deep-Sea Res., Part II, 49, 509-543.

Coale, K. H., et al. (1996), A massive phytoplankton bloom induced by an ecosystem-scale iron fertilization experiment in the equatorial Pacific Ocean, Nature, 383(6600), 495-501.

Craig, H., and T. Hayward (1987), Oxygen supersaturation in the ocean: biological versus physical contributions, Science, 235, 199-202.

Cresswell, G. R. (2000), Coastal currents of northern Papua New Guinea, and the Sepik River outflow, Mar. Freshwater Res., 51(6), 553-564.

Dam, H. G., X. S. Zhang, M. Butler, and M. R. Roman (1995), Mesozooplankton grazing and metabolism at the equator in the central Pacific Implications for carbon and nitrogen fluxes, Deep-Sea Res., Part II, 42(2-3), 735-756.

Dugdale, R. C., and F. P. Wilkerson (1998), Silicate regulation of new production in the equatorial Pacific upwelling, Nature, 391(6664), 270-273.

Dugdale, R. C., F. P. Wilkerson, R. T. Barber, and F. P. Chavez (1992), Estimating new production in the equatorial Pacific Ocean at $150 \mathrm{~W}$, J. Geophys. Res., 97(C1), 681-686.

Dugdale, R. C., F. P. Wilkerson, F. Chai, and R. Feely (2007), Size-fractionated nitrogen uptake measurements in the equatorial Pacific and confirmation of the low Si-high-nitrate low-chlorophyll condition, Global Biogeochem. Cycles, 21(2), GB2005, doi:10.1029/2006GB002722.

Dunne, J. P., J. W. Murray, M. Rodier, and D. A. Hansell (2000), Export flux in the western and central equatorial Pacific: Zonal and temporal variability, Deep-Sea Res., Part I, 47(5), 901-936.

Dunne, J. P., R. A. Armstrong, A. Gnanadesikan, and J. L. Sarmiento (2005), Empirical and mechanistic models for the particle export ratio, Global Biogeochem. Cycles, 19, GB4026, doi:10.1029/2004GB002390.

Eldin, G., and M. Rodier (2003), Ocean physics and nutrient fields along 180 degrees during an El Nino-Southern Oscillation cold phase, J. Geophys. Res., 108(C12), 8137, doi:10.1029/2000JC000746.

Emerson, S. (1987), Seasonal oxygen cycles and biological new production in surface waters of the sub-Arctic Pacific-Ocean, J. Geophys. Res., 92(C6), 6535-6544.

Emerson, S., P. Quay, C. Stump, D. Wilbur, and R. Schudlich (1995), Chemical tracers of productivity and respiration in the subtropical Pacific Ocean, J. Geophys. Res., 100(C8), 15873-15887.

Emerson, S., C. Stump, and D. Nicholson (2008) Net biological oxygen production in the ocean: Remote in situ measurements of O-2 and N-2 in surface waters, Global Biogeochem. Cycles, 22(3), GB3023, doi:10.1029/2007GB003095.

Eppley, R. W., and B. J. Peterson (1979), Particulate organic matter flux and planktonic new production in the deep ocean, Nature, 282(677-680).

Feely, R. A., T. Takahashi, R. Wanninkhof, M. J. McPhaden, C. E. Cosca S. C. Sutherland, and M. E. Carr (2006), Decadal variability of the air-sea $\mathrm{CO} 2$ fluxes in the equatorial Pacific Ocean, J. Geophys. Res., 111(C8), C08S90, doi:10.1029/2005JC003129.

Fine, R. A., R. Lukas, F. M. Bingham, M. J. Warner, and R. H. Gammon (1994), The western equatorial Pacific - a water mass crossroads, J. Geophys. Res., 99(C12), 25,063-25,080.

Garcia, H. E., and L. I. Gordon (1992) Oxygen solubility in water: better fitting equations, Limnol. Oceanogr., 37(6), 1307-1312.

Gruber, N., C. D. Keeling, and T. F. Stocker (1998), Carbon-13 constraints on the seasonal inorganic carbon budget at the BATS site in the northwestern Sargasso Sea, Deep-Sea Res., Part I, 45(4-5), 673-717.
Hamme, R. C., and S. Emerson (2004), The solubility of neon, nitrogen and argon in distilled water and seawater, Deep-Sea Res., Part I, 51(11), 1517-1528.

Hendricks, M. B., M. L. Bender, and B. A. Barnett (2004), Net and gross O-2 production in the Southern Ocean from measurements of biological O-2 saturation and its triple isotope composition, Deep-Sea Res., Part I, 51(11), 1541-1561.

Hendricks, M. B., M. L. Bender, B. A. Barnett, P. Strutton, and F. P. Chavez (2005), Triple oxygen isotope composition of dissolved O-2 in the equatorial Pacific: A tracer of mixing, production, and respiration, J. Geophys. Res., 110(C12), C12021, doi:10.1029/2004JC002735.

Jenkins, W. J. (1988), Nitrate flux into the euphotic zone near Bermuda, Nature, 331(6156), 521-523.

Jenkins, W. J., and S. C. Doney (2003), The subtropical nutrient spiral, Global Biogeochem. Cycles, 17(4), 1110, doi:10.1029/2003GB002085.

Johnson, G. C., M. J. McPhaden, and E. Firing (2001), Equatorial Pacific ocean horizontal velocity, divergence, and upwelling, J. Phys. Oceanogr., 31(3), 839-849.

Juranek, L. W., and P. D. Quay (2005), In vitro and in situ gross primary and net community production in the North Pacific Subtropical Gyre using labeled and natural abundance isotopes of dissolved O-2, Global Biogeochem. Cycles, 19(3), GB3009, doi:10.1029/2004GB002384.

Kaiser, J., M. K. Reuer, B. Barnett, and M. L. Bender (2005), Marine productivity estimates from continuous $\mathrm{O}-2 / \mathrm{Ar}$ ratio measurements by membrane inlet mass spectrometry, Geophys. Res. Lett., 32(19), L19605, doi:10.1029/2005GL023459.

Keeling, C. D., H. Brix, and N. Gruber (2004), Seasonal and long-term dynamics of the upper ocean carbon cycle at Station ALOHA near Hawaii, Global Biogeochem. Cycles, 18(4), GB4006, doi:10.1029/ 2004GB002227.

Lämmerzahl, P., T. Röckmann, C. A. M. Brenninkmeijer, D. Krankowsky, and K. Mauersberger (2002), Oxygen isotope composition of stratospheric carbon dioxide, Geophys. Res. Lett., 29(12), 1582, doi:10.1029/ 2001 GL014343

Laws, E. A. (1991), Photosynthetic quotients, new production and net community production in the open ocean, Deep-Sea Res., Part I, 38(1) 143-167.

Laws, E. A., P. G. Falkowski, W. O. Smith, H. Ducklow, and J. J. McCarthy (2000), Temperature effects on export production in the open ocean, Global Biogeochem. Cycles, 14(4), 1231-1246.

Le Borgne, R., R. T. Barber, T. Delcroix, H. Y. Inoue, D. J. Mackey, and M. Rodier (2002), Pacific warm pool and divergence: temporal and zonal variations on the equator and their effects on the biological pump, DeepSea Res., Part II, 49(13-14), 2471-2512.

Le Bouteiller, A., A. Leynaert, M. R. Landry, R. Le Borgne, J. Neveux, M. Rodier, J. Blanchot, and S. L. Brown (2003), Primary production, new production, and growth rate in the equatorial Pacific: Changes from mesotrophic to oligotrophic regime, J. Geophys. Res., 108(C12), 8141, doi:10.1029/2001JC000914.

Ledwell, J. R., A. J. Watson, and C. S. Law (1993), Evidence for Slow Mixing across the Pycnocline from an Open-Ocean Tracer-Release Experiment, Nature, 364(6439), 701-703.

Ledwell, J. R., A. J. Watson, and C. S. Law (1998) Mixing of a tracer in the pycnocline, J. Geophys. Res., 103(C10), 21,499-21,529.

Lindstrom, E., R. Lukas, R. Fine, E. Firing, S. Godfrey, G. Meyers, and M. Tsuchiya (1987), The Western Equatorial Pacific-Ocean Circulation Study, Nature, 330(6148), 533-537.

Lukas, R., and E. Lindstrom (1991), The Mixed Layer of the Western Equatorial Pacific-Ocean, J. Geophys. Res., 96, 3343-3357.

Luz, B., and E. Barkan (2000), Assessment of oceanic productivity with the triple-isotope composition of dissolved oxygen, Science, 288(5473) 2028-2031

Luz, B., and E. Barkan (2005), The isotopic ratios O-17/O-16 and O-18/ $\mathrm{O}-16$ in molecular oxygen and their significance in biogeochemistry, Geochim. Cosmochim. Acta, 69(5), 1099-1110.

Luz, B., and E. Barkan (2009), Net and gross oxygen production from O-2 Ar, O-17/O-16 and O-18/O-16 ratios, Aquat. Microb. Ecol., 56(2-3), $133-145$.

Luz, B., E. Barkan, M. L. Bender, M. H. Thiemens, and K. A. Boering (1999), Triple-isotope composition of atmospheric oxygen as a tracer of biosphere productivity, Nature, 400(6744), 547-550.

Marra, J. (2002), Approaches to the Measurement of Plankton Production, 31 pp., Blackwell, Malden, MA.

Masunaga, H., T. S. L'Ecuyer, and C. D. Kummerow (2005), Variability in the characteristics of precipitation systems in the tropical Pacific. Part 1 : Spatial structure, J. Clim., 18(6), 823-840. 
Matsumoto, K., K. Furuya, and T. Kawano (2004), Association of picophytoplankton distribution with ENSO events in the equatorial Pacific between 145 degrees E and 160 degrees W, Deep-Sea Res., Part I, 51(12), 1851-1871.

McCarthy, J. J., C. Garside, J. L. Nevins, and R. T. Barber (1996), New production along 140 degrees $\mathrm{W}$ in the equatorial Pacific during and following the 1992 El Nino event, Deep-Sea Res., Part II, 43(4-6), 1065-1093.

Meinen, C. S., M. J. McPhaden, and G. C. Johnson (2001) Vertical velocities and transports in the equatorial Pacific during 1993-99, J. Phys. Oceanogr., 31(11), 3230-3248.

Millero, F. J., and A. Poisson (1981), International one-atmosphere equation of state of seawater, Deep-Sea Res., Part I, 28(6), 625-629.

Moore, J. K., S. C. Doney, and K. Lindsay (2004), Upper ocean ecosystem dynamics and iron cycling in a global three-dimensional model, Global Biogeochem. Cycles, 18(4), GB4028, doi:10.1029/2004GB002220.

Murray, J. W., R. T. Barber, M. R. Roman, M. P. Bacon, and R. A. Feely (1994), Physical and biological-controls on carbon cycling in the equatorial Pacific, Science, 266(5182), 58-65.

Murray, J. W., E. Johnson, and C. Garside (1995), A Us Jgofs process study in the equatorial Pacific (Eqpac) - Introduction, Deep-Sea Res., Part II, 42(2-3), 275-293.

Peterson, B. J. (1980), Aquatic primary productivity and the C-14-Co2 method - A history of the productivity problem, Annu. Rev. Ecol. Evol. S., 11, 359-385.

Raimbault, P., G. Slawyk, B. Boudjellal, C. Coatanoan, P. Conan, B. Coste, N. Garcia, T. Moutin, and M. Pujo-Pay (1999), Carbon and nitrogen uptake and export in the equatorial Pacific at 150 degrees W: Evidence of an efficient regenerated production cycle, J. Geophys. Res., 104(C2), 3341-3356.

Reuer, M. K., B. A. Barnett, M. L. Bender, P. G. Falkowski, and M. B Hendricks (2007), New estimates of Southern Ocean biological production rates from $\mathrm{O}-2 / \mathrm{Ar}$ ratios and the triple isotope composition of $\mathrm{O}-2$ Deep-Sea Res., Part I, 54(6), 951-974.

Rivkin, R. B., and L. Legendre (2001), Biogenic carbon cycling in the upper ocean: Effects of microbial respiration, Science, 291(5512), 2398-2400.

Rodier, M., and R. Le Borgne (1997), Export flux of particles at the equator in the western and central Pacific ocean, Deep-Sea Res., Part II, 44 (910), 2085-2113.

Ryan, J. P., I. Ueki, Y. Chao, H. C. Zhang, P. S. Polito, and F. P. Chavez (2006), Western Pacific modulation of large phytoplankton blooms in the central and eastern equatorial Pacific, J. Geophys. Res., 111(G2), G02013, doi:10.1029/2005JG000084

Sarma, V., O. Abe, and T. Saino (2006), Underway surface water sample collection system for dissolved gases and triple isotopic composition of dissolved oxygen, Geochim. Cosmochim. Acta, 70(18), A557-A557.

Schlitzer, R. (2004), Export production in the equatorial and North Pacific derived from dissolved oxygen, nutrient and carbon data, J. Oceanogr., 60(1), 53-62.

Simons, F. J., M. T. Zuber, and J. Korenaga (2000), Isostatic response of the Australian lithosphere: Estimation of effective elastic thickness and anisotropy using multitaper spectral analysis, J. Geophys. Res., 105(B8), 19,163-19,184.
Slawyk, G., and J. J. Macisaac (1972), Comparison of 2 automated ammonium methods in a region of coastal upwelling, Deep-Sea Res., 19(7), 521-\&.

Slemons, L. O., J. W. Murray, J. Resing, B. Paul, and P. Dutrieux (2010), Western Pacific coastal sources of iron, manganese, and aluminum to the Equatorial Undercurrent, Global Biogeochem. Cycles, 24, GB3024, doi:10.1029/2009GB003693

Spitzer, W. S., and W. J. Jenkins (1989), Rates of vertical mixing, gasexchange and new production-estimates from seasonal gas cycles in the upper ocean near Bermuda, J. Mar. Res., 47(1), 169-196.

Stanley, R. H. R. (2007), Air-Sea Gas Exchange and Upper Ocean Biological Production, Ph.D Thesis, MIT/WHOI Joint Program, Woods Hole.

Stanley, R. H. R., W. J. Jenkins, and S. C. Doney (2006), Quantifying seasonal air-sea gas exchange processes using noble gas time series: A design experiment, J. Mar. Res., 64(2), 267-295.

Stanley, R. H. R., W. J. Jenkins, S. C. Doney, and D. E. Lott III (2009), Noble gas constraints on air-sea gas exchange and bubble fluxes, J. Geophys. Res., 114(C11), C11020, doi:10.1029/2009JC005396.

Strickland, J. D. H., and T. R. Parsons (1972), A Practical Handbook of Seawater Analysis, Fisheries Research Board of Canada, Ottawa.

Strutton, P. G., W. Evans, and F. P. Chavez (2008), Equatorial Pacific chemical and biological variability, 1997-2003, Global Biogeochem. Cycles, 22(2), GB2001, doi:10.1029/2007GB003045.

Takahashi, T., R. A. Feely, R. F. Weiss, R. H. Wanninkhof, D. W. Chipman, S. C. Sutherland, and T. T. Takahashi (1997), Global air-sea flux of CO2: An estimate based on measurements of sea-air $\mathrm{pCO}(2)$ difference, in Proc. Natl. Acad. Sci. U. S. A., 94(16), 8292-8299.

Takahashi, T., et al. (2002) Global sea-air CO2 flux based on climatological surface ocean $\mathrm{pCO}(2)$, and seasonal biological and temperature effects, Deep-Sea Res., Part II, 49(9-10), 1601-1622.

Takahashi, T., S. C. Sutherland, R. A. Feely, and C. E. Cosca (2003), Decadal variation of the surface water $\mathrm{PCO} 2$ in the western and central equatorial Pacific, Science, 302(5646), 852-856.

Thiemens, M. H., T. Jackson, E. C. Zipf, P. W. Erdman, and C. Vanegmond (1995), Carbon-dioxide and oxygen-isotope anomalies in the mesosphere and stratosphere, Science, 270(5238), 969-972.

Turk, D., M. R. Lewis, G. W. Harrison, T. Kawano, and I. Asanuma (2001), Geographical distribution of new production in the western central equatorial Pacific during El Nino and non-El Nino conditions, J. Geophys. Res., 106(C3), 4501-4515.

Wanninkhof, R. (1992), Relationship between wind speed and gas exchange over the ocean, J. Geophys. Res., 97(C5), 7373-7382.

Wolter, K., and M. S. Timlin (1998), Measuing the strength of ENSO events: How does the 1997/98 rank?, Weather, 53, 315-324.

B. A. Barnett and M. L. Bender, Department of Geosciences, Princeton University, Princeton, NJ 08544, USA.

N. Cassar, Division of Earth and Ocean Sciences, Duke University, Durham, NC 27708, USA.

J. B. Kirkpatrick, School of Oceanography, University of Washington, Seattle, WA 98195, USA

R. H. R. Stanley, Department of Marine Chemistry and Geochemistry, Woods Hole Oceanographic Institution, 266 Woods Hole Rd., Woods Hole, MA 02543, USA. (rstanley@whoi.edu) 